This item was submitted to Loughborough's Research Repository by the author.

Items in Figshare are protected by copyright, with all rights reserved, unless otherwise indicated.

\title{
Design optimization study of a nonlinear energy absorber for internal combustion engine pistons
}

PLEASE CITE THE PUBLISHED VERSION

https://doi.org/10.1115/1.4040239

\section{PUBLISHER}

(c) ASME (American Society of Mechanical Engineers)

\section{VERSION}

AM (Accepted Manuscript)

\section{PUBLISHER STATEMENT}

This work is made available according to the conditions of the Creative Commons Attribution 4.0 International (CC BY 4.0) licence. Full details of this licence are available at: http://creativecommons.org/licenses/by/4.0/

\section{LICENCE}

CC BY 4.0

\section{REPOSITORY RECORD}

Dolatabadi, Nader, Stephanos Theodossiades, and Steve Rothberg. 2019. "Design Optimization Study of a Nonlinear Energy Absorber for Internal Combustion Engine Pistons". figshare. https://hdl.handle.net/2134/33060. 


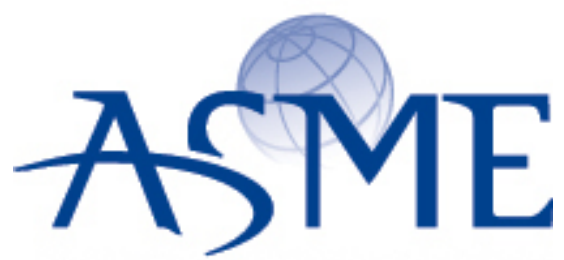

\title{
American Society of Mechanical Engineers
}

SETTING THE STANDARD

ASME Accepted Manuscript Repository

Institutional Repository Cover Sheet

N. Dolatabadi, S. Theodossiades and S. J. Rothberg

Authors:

Journal of Computational and Nonlinear Dynamics

ASME Journal Title:

Design optimization study of a nonlinear energy absorber for internal combustion engine pistons ASME Paper Title:

\begin{abstract}
Date of Publication (VOR* Online)
Jul 26, 2018

Volume/Issue _ $13(9)$

http://computationalnonlinear.asmedigitalcollection.asme.org/article.aspx?articleid=2681664

ASME Digital Collection URL:
\end{abstract}

$10.1115 / 1.4040239$

DOI:

*VOR (version of record) 


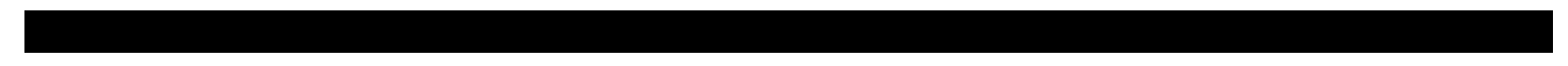




\title{
Design Optimisation Study of a Nonlinear Energy Absorber for Internal Combustion Engine Pistons
}

\author{
N. Dolatabadi, S. Theodossiades, S.J. Rothberg \\ Wolfson School of Mechanical, Electrical and Manufacturing Engineering, Loughborough University \\ Leicestershire, LE11 3TU, UK
}

\begin{abstract}
Piston impacts against the cylinder liner are the most significant sources of mechanical noise in internal combustion engines. Traditionally, the severity of impacts is reduced through the modification of physical and geometrical characteristics of components in the piston assembly. These methods effectively reduce power losses at certain engine operating conditions. Frictional losses and piston impact noise are inversely proportional. Hence, reduction in power loss leads to louder piston impact noise. An alternative method that is robust to fluctuations in engine operating conditions is anticipated to improve the engine's NVH performance, whilst exacerbation in power loss remains within the limits of conventional methods. The concept of Targeted Energy Transfer (TET) through the use of Nonlinear Energy Sinks (NES) is relatively new and its application in automotive powertrains has not been demonstrated yet. In this paper, a TET device is conceptually designed and optimised through a series of parametric studies. The dynamic response and power loss of a piston model equipped with this nonlinear energy sink is investigated. Numerical studies have shown a potential in reducing the severity of impact dynamics by controlling piston's secondary motion.
\end{abstract}

Keywords: Piston impact; Piston secondary motion; Targeted energy transfer; Nonlinear energy sink; Friction; Power loss.

\section{Introduction}

The dominance of internal combustion (IC) engines in transport raises concerns about their environmental effects, such as fuel supply, air pollution and noise emissions. Despite the high environmental impact of the emitted particulates, noise emissions cannot be neglected either, especially for urban driving conditions [1-3]. Noise and vibration in IC engines are mainly caused by the combustion process and mechanical excitation. The loudest sources of mechanical excitation are the piston impacts against the cylinder liner [4], which are initiated by piston's secondary motion (translation and rotation) inside the piston-cylinder clearance. 
Characterisation of the influential factors on piston's secondary motion leads to better understanding and control of the occurring impacts. The influential factors are classified to those related to the engine operating conditions and those related to the geometrical and physical characteristics of the piston assembly components. The engine-operation related factors are the speed, load and combustion delay [5-7] with the engine speed being the most significant factor amongst them. The impact force increases as the engine speed increases, whilst piston impact noise is rather insensitive to load at higher engine speeds $[5,6]$. Combustion delay results in greater contact forces, as the connecting rod is at an angle with respect to the cylinder axis when the peak pressure takes place [7]. Piston impacts are conventionally controlled through the geometrical and physical factors, since fluctuation in engine operating conditions is essential for vehicle’s performance. The physical factors are piston-pin offset, crankshaft offset, piston-cylinder clearance, piston-skirt stiffness, piston mass and location of piston's centre of gravity [8-12]. There are two downsides to the optimisation of geometrical factors: (i) trade-off between friction loss and NVH is required [11, 12] and (ii) the modified parameters are only effective within specific range(s) of the engine speed [13]. The clearance size and crankshaft offset are the most influential factors in this category. Tighter clearance improves the NVH performance, whilst friction (power) loss increases. The power losses increase as the engine speed increases for the same clearance size [12, 13]. The crankshaft offset improves the NVH performance noticeably at lower engine speeds. This improvement deteriorates as the engine speed increases [11]. Therefore, a passive control method that is robust to engine operating conditions is highly favoured to reduce the piston impact severity, whilst the friction (power) losses remain below the limits of the conventional control methods.

The concept of targeted energy transfer (TET) through the use of nonlinear energy sinks (NES) is suitable for the passive control of transient oscillations. The NES is an oscillator with essential stiffness nonlinearity possessing negligible or very small linear damping [14]. This class of nonlinear systems can effectively capture transient resonances, transfer broadband vibration energy between the NES and its primary system and localise the vibrations to nonlinear normal modes of the NES [14]. Past studies are allocated to the excitation of the primary systems through an initial impulsive force [15, 18]. Recently, studies have focused on the external periodic forcing of the primary system in conjunction with the NES [14, 20]. The application of NES to automotive powertrains (especially on the transient, nonlinear dynamics of the piston assembly) is a novel concept that has not been reported yet. Computational parametric studies are commonly exploited to identify NES design parameters such that the oscillations of the primary system are either suppressed or completely eliminated [21, 22]. 
This paper is dealing with the performance analysis of the NES mechanism in an internal combustion engine piston model. Spectral characteristics of piston's secondary motion are exploited to determine the NES design. The dynamics of piston's secondary motion are described in the presence of the NES attachment. The performance objective functions are determined using the dynamic response of the system. These objective functions are optimised through a series of parametric studies. The power loss of the piston equipped with the NES is evaluated for the optimal designs. The NES performance is compared against the conventional control methods for piston's secondary motion. The optimum NES design is selected using both dynamic response and power loss criteria.

\section{Piston dynamics model and NES design}

The equations for piston's secondary motion are usually described using piston eccentricities (Equation 1) [23, 27]. The model of figure 1 has two degrees of freedom, namely the top and bottom piston skirt eccentricities $\left(e_{t}\right.$ and $\left.e_{b}\right)$. $m_{p i s}$ and $m_{\text {pin }}$ are the piston and pin masses. $I_{\text {pis }}$ is the piston inertia about the pin centre of rotation. $\ddot{e}_{t}$ and $\ddot{e}_{b}$ are eccentricity accelerations. The piston side force $\left(F_{t}\right)$ is mainly determined by the combustion and piston inertia forces (Equation 2). The effect of friction force and moment $\left(F_{f}\right.$ and $\left.M_{f}\right)$ on the impact load is negligible [28]. Since $d_{p}$ and $d_{g}$ equal zero for the piston in the engine under examination, the combined moment of combustion force and piston inertia about the pin axis $\left(M_{S}\right)$ is trivial. A single-cylinder, four-stroke motorbike engine is utilised in this study due to its high speed and load capacity, which is compatible to most commercially available engines (OEM and motorsports).

$\left[\begin{array}{cc}m_{\text {pis }}\left(1-\frac{b}{L_{s}}\right)+m_{\text {pin }}\left(1-\frac{a}{L_{s}}\right) & m_{\text {pis }} \frac{b}{L_{s}}+m_{\text {pin }} \frac{a}{L_{s}} \\ \frac{I_{p i s}}{L_{s}}+m_{p i s}(a-b)\left(1-\frac{a}{L_{s}}\right) & -\frac{I_{p i s}}{L_{s}}+m_{p i s}(a-b) \frac{b}{L_{s}}\end{array}\right]\left\{\begin{array}{c}\ddot{e}_{t} \\ \ddot{e}_{b}\end{array}\right\}=\left\{\begin{array}{c}\sum F_{H} \mp F_{f} \tan \phi-F_{t} \\ \sum M_{H}+M_{f}+M_{s}\end{array}\right\}$

$F_{t}=\left(-m_{p i n} \ddot{x}-m_{p i s} \ddot{x}+F_{G}\right) \tan \phi$

The contact forces at the piston-cylinder conjunction $\left(F_{h y d}\right)$ are predicted using an elasto-hydrodynamic lubrication model (EHL) $[23,25]$. On the other hand, a 'dry' contact model is desirable in parametric studies for its computational efficiency [29]. In this model, the contact loads are supported by the damping and stiffness of the mating structures at the four corners of the piston's skirt. The stiffness properties are estimated using Hertz contact theory for circular contacts [30-32]. The piston and cylinder liner are made of aluminium. The damping ratio of aluminium reportedly varies between 0.0001 and 0.01 with respect to its shape, dimensions of the structure and operating conditions [33, 34]. The structural damping 
ratios (for six- and four-cylinder engine geometries) vary between 0.01 and 0.0378 [35, 36]. Thus, an invariant damping ratio of $\zeta=0.003$ is assumed to represent conditions for impact dynamics. Equation 3 describes the total force $\left(F_{H}\right)$ for the 'dry' contact model. Subscripts A and C indicate the top and bottom of the piston skirt at the thrust side (TS) and subscripts B and D signify the top and bottom piston skirt corners at the anti-thrust side (ATS).

$F_{\text {hyd }} \equiv F_{H, i}=k_{H} \delta^{\frac{3}{2}}-c_{H} \dot{\delta}, \quad\left(k_{H}=\frac{4}{3} E \sqrt{R}, \quad i=A, B, C, D,\right)$

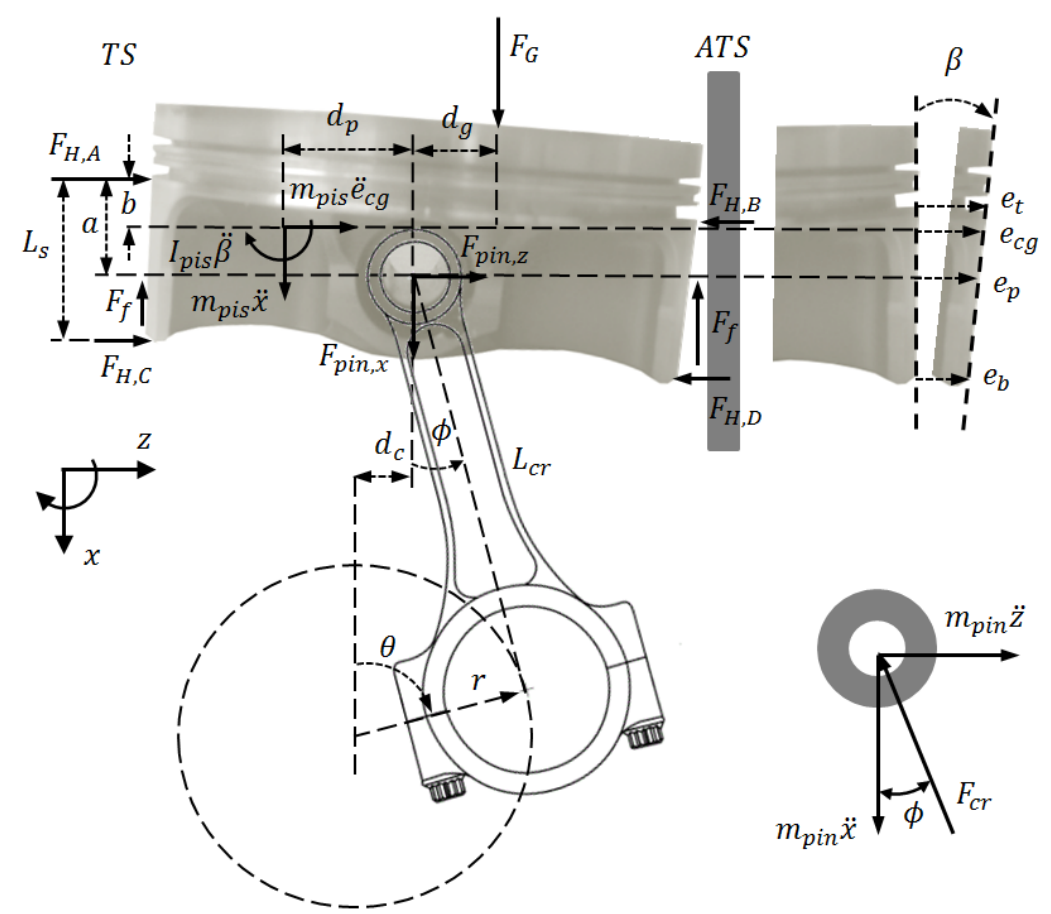

Figure 1: Piston assembly parameters and free body diagram

\section{NES design}

The potential NES design should be as robust as possible to system uncertainties, initial conditions and external excitations. The applicability of passive NES to piston's secondary motion and its satisfactory operation rely on the good understanding of system dynamics through spectral analysis (Figure 2). The rotational frequency of the crankshaft is $50 \mathrm{~Hz}$ for a single-cylinder four-stroke engine operating at 3000rpm. This frequency is known as the first engine order. Combustion excitations are related to half engine order in the four-stroke cycle. Mechanical excitations (piston impacts, big-end bearing impacts etc.) appear at multiples of the engine order [37]. Mechanical excitations possess higher spectral amplitudes than combustion during piston's secondary motion (Figure 2). Piston rotation $(\beta)$ undergoes amplitudes with one order of magnitude higher than the piston translation $\left(e_{p}\right)$ at the first and second engine orders (50 and $\left.100 \mathrm{~Hz}\right)$. Thus, 
the NES design should primarily target piston rotation in an attempt to effectively control the number and severity of impacts.
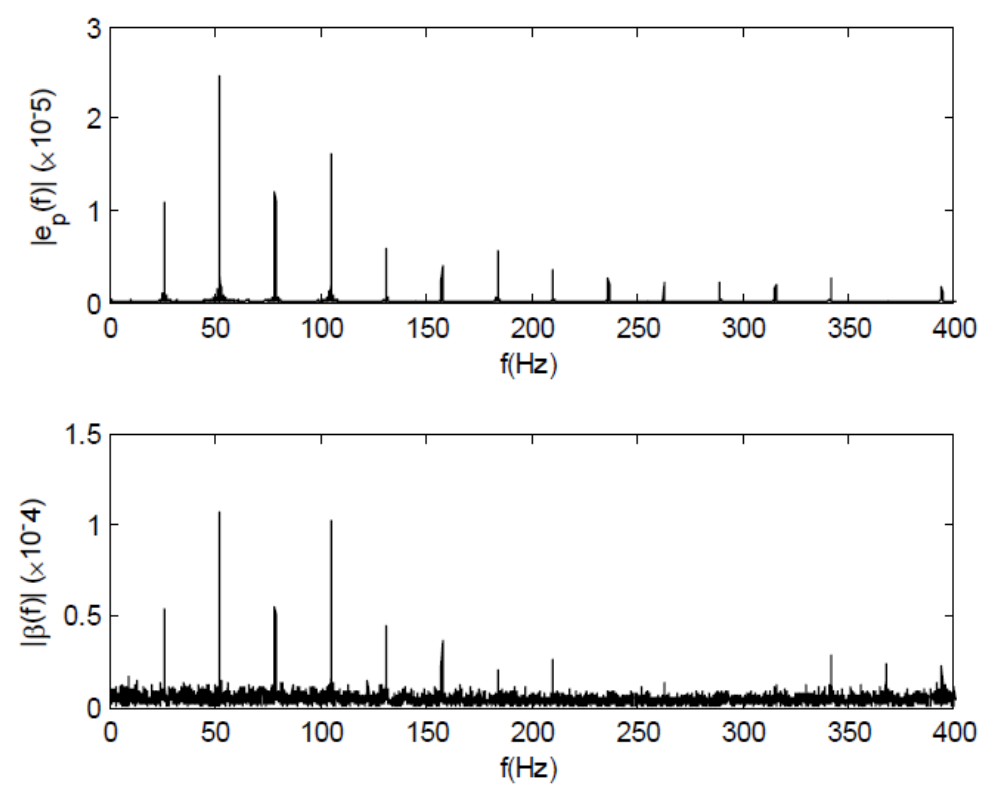

Figure 2: FFT spectra of piston's secondary motions at 3000rpm: translation $\left(e_{p}\right)$ and rotation about the piston pin $(\beta)$

The primary NES design can be a pendulum that is affecting the rotational motion of the piston (Figure 3). The pendulum mechanism rotates about the piston pin and reacts to piston rotation through a torsional spring with essentially cubic nonlinearity $\left(k_{t}(\gamma-\beta)^{3}\right)$. The stiffness nonlinearity aims to establish communication between the NES and the primary system for a broad band of excitation frequencies. The excess of energy transferred to the NES is dissipated through a weak linear damper (also torsional, $c_{t}(\dot{\gamma}-\dot{\beta})$ ). The assumptions employed in this concept are as follows: (i) the pendulum has lump mass $\left(m_{t}\right)$ located at its free end, (ii) the masses of the link, spring and damper are negligible and the centre of gravity of the pendulum coincides with the location of the lumped mass, (iii) the equilibrium position is aligned with the axis of the cylinder liner for both pendulum and piston and (iv) the friction and clearance are trivial at the pendulum's pivot point. Equation 4 shows the relation between piston translation $(z)$ and pendulum rotation $(\gamma)$. Therefore, the pendulum mechanism is responsive to both piston rotation and translation. Moreover, the pendulum reacts to the primary acceleration of the piston $(\ddot{x})$, being receptive to combustion and inertial excitations. In this paper, a single pendulum NES mechanism is exploited to study the influence on piston's secondary motion. 
$\ddot{z}_{t}=\ddot{z}-L_{t} \ddot{\gamma} \cos \gamma+L_{t} \dot{\gamma}^{2} \sin \gamma$

$\ddot{x}_{t}=\ddot{x}-L_{t} \ddot{\gamma} \sin \gamma-L_{t} \dot{\gamma}^{2} \cos \gamma$

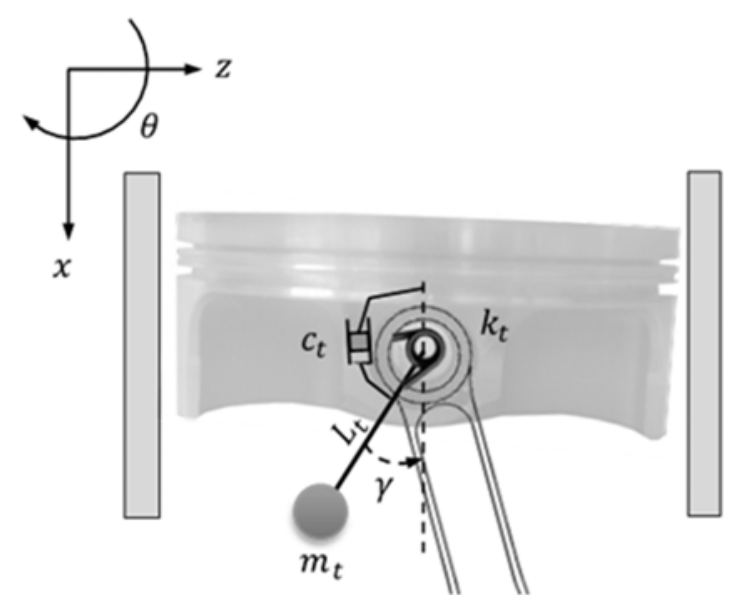

Figure 3: Pendulum NES coupled with the piston assembly

\section{Dynamics model for piston equipped with NES}

The free body diagram of the NES pendulum is presented in figure 4. The reaction forces and moments are indicated at the pin location $\left(F_{t, z}, F_{t, x}\right.$ and $\left.M_{t}\right)$. The other parameters and forces are the same as in the 2-DOF model. The equations for the 3-DOF model are derived in a similar way as in the 2-DOF model through a combined analysis of figures 1 and 4 . The inertia matrix $(\boldsymbol{M})$ and force array $(\boldsymbol{F})$ are described in equations 5 and 6, successively. Subscript $i$ indicates the piston skirt corners $(i=A, B, C, D)$. The dynamics of motion for piston with pendulum NES are given in equation 7. The piston rotation $(\beta)$ is defined in terms of piston eccentricities [25]. The system of Equations 7 is solved, and the components' motions are evaluated through predictor-corrector integration [24].
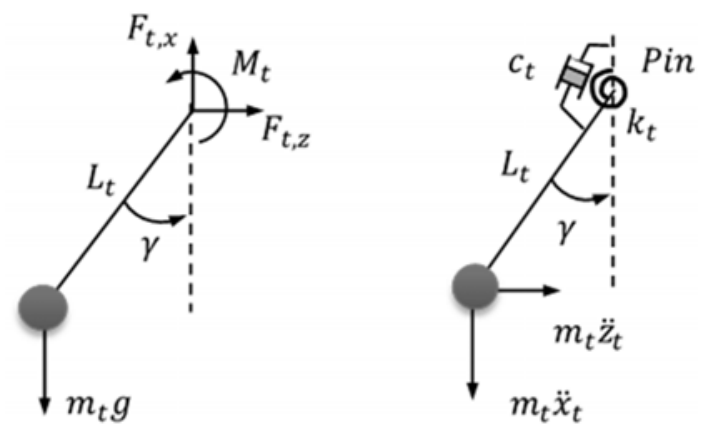

Figure 4: Free body diagram of the pendulum NES (external excitations and inertial forces)

S. Theodossiades, CND-17-1339 


$$
\begin{aligned}
& {\left[\begin{array}{ccc}
m_{\text {pis }}\left(1-\frac{b}{L_{s}}\right)+\left(m_{\text {pin }}+m_{t}\right)\left(1-\frac{a}{L_{s}}\right) & m_{\text {pis }} \frac{b}{L_{s}}+\left(m_{\text {pin }}+m_{t}\right) \frac{a}{L_{s}} & m_{t} L_{t}(-\cos \gamma+\sin \gamma \tan \phi) \\
\frac{I_{p}}{L_{s} C}+m_{\text {pis }}\left(1-\frac{b}{L_{s}}\right)(a-b) & -\frac{I_{p}}{L_{s} C}+m_{\text {pis }} \frac{b}{L_{s}}(a-b) & 0 \\
-m_{t} L_{t}\left(1-\frac{a}{L_{s}}\right) \cos \gamma & -m_{t} L_{t} \frac{a}{L_{s}} \cos \gamma & m_{t} L_{t}^{2}
\end{array}\right]} \\
& \left\{\begin{array}{c}
{\left[-F_{G}+m_{p i s} \ddot{x}+m_{p i n} \ddot{x}+m_{t}\left(\ddot{x}-L_{t} \dot{\gamma}^{2} \cos \gamma-g\right)\right] \tan \phi-m_{t} L_{t} \dot{\gamma}^{2} \sin \gamma+\sum F_{H, i}} \\
m_{p i s} \ddot{x} d_{p}+F_{G} d_{g}+\left(F_{H, A}+F_{H, B}\right) a-\left(F_{H, C}+F_{H, D}\right)\left(L_{s}-a\right)+k_{t}(\gamma-\beta)^{3}+c_{t}(\dot{\gamma}-\dot{\beta}) \\
m_{t}(\ddot{x}-g) L_{t} \sin \gamma-k_{t}(\gamma-\beta)^{3}-c_{t}(\dot{\gamma}-\dot{\beta})
\end{array}\right\} \\
& \boldsymbol{M}_{3 \times 3}\left\{\begin{array}{c}
\ddot{e}_{t} \\
\ddot{e}_{b} \\
\ddot{\gamma}
\end{array}\right\}=\boldsymbol{F}=\left\{\begin{array}{c}
F \\
M_{1} \\
M_{2}
\end{array}\right\}
\end{aligned}
$$

\section{The study of the NES performance}

The NES design parameters are determined prior to any performance studies. The performance objective functions and power loss calculations are described in relation with the design parameters.

\section{NES design parameters}

The mass, length, stiffness and damping parameters of the pendulum NES are unknown. These parameters determine the NES performance (and the corresponding frequency content of NES oscillations). The same performance can be achieved for different combinations of those parameters. Provided one of the parameters is assumed as invariable, such overlaps can be avoided. The NES stiffness has paramount effect on energy transfer. The added mass of the NES affects the engine performance. The damping determines the dissipative behaviour of the NES and its participation in the parametric study is essential. The pendulum motion is physically restricted by the cylinder bore and piston skirt dimensions. Thus, the length of the pendulum is assumed as constant $(0.05 \mathrm{~m})$. The selected length allows for large angular oscillations of the pendulum inside the cylinder bore whilst its contact with piston skirt is avoided. The pendulum oscillations are aggressive for $k_{t}$ smaller than $10 \mathrm{Nm} / \mathrm{rad}^{3}$ and NES impacts with the cylinder liner are inevitable. For $k_{t}$ greater than $110 \mathrm{Nm} / \mathrm{rad}^{3}$, the angular oscillations are trivial, and the dissipation mechanism prevails. Therefore, the stiffness coefficient is varied between $10-110 \mathrm{Nm} / \mathrm{rad}^{3}$ with $5 \mathrm{Nm} / \mathrm{rad}^{3}$ steps. The damping coefficient is varied between $0-0.04 \mathrm{Nms} / \mathrm{rad}$ with $0.005 \mathrm{Nms} / \mathrm{rad}$ steps. The NES mass ratio $(\varepsilon)$ is described as a percentage of the NES mass over the mass of the primary 
system $\left(\varepsilon=100 m_{t} /\left(m_{p i s}+m_{\text {pin }}\right)\right)$. The upper limit of the mass ratio is restricted to $20 \%$ [38] and the mass ratio is varied between 5 - 20\% with $2.5 \%$ steps.

\section{Performance objective functions}

The aim of the NES is to control piston's secondary motion. The performance objective functions are determined using piston dynamics. Piston impact events are monitored through three criteria: (i) impact severity, (ii) number of impacts and (iii) energy transfer. The impact severity is identified by the maxima of the eccentricity accelerations $\left(\ddot{e}_{t}\right.$ and $\left.\ddot{e}_{b}\right)$ over one engine cycle. In order to mathematically determine this objective function, the maximum or minimum value of eccentricity accelerations should be replaced with variable " $V$ " in equation 9 for both the 3-DOF and 2-DOF systems. The number of impacts is extracted at the top and bottom of the piston skirt using eccentricity displacements $\left(e_{t}\right.$ and $\left.e_{b}\right)$. The energy transfer criterion shows the amount of induced energy in the cylinder structure by piston impacts (Equation 8) at the TS and ATS of the cylinder liner over one engine cycle. The transferred energy at each side is the total impact energy at the top and bottom of the piston skirt (subscripts $t$ and $b$ ). Variable $\delta$ is the deformation in the contact area and $F_{H}$ is the contact force. These criteria denote the percentage of variations in the objective functions with respect to the 2-DOF system (Equation 9). The variable $(V)$ is essentially the parameter for each criterion (objective function). Positive variations indicate improvement in the performance of the NES. Contour plots are useful tools to understand the correlation between each objective function and the design parameters.

$$
\begin{aligned}
& E T=\oint F_{H, t} d \delta_{t}+\oint F_{H, b} d \delta_{b} \\
& \% \Delta V=\frac{V_{3 d o f}-V_{2 d o f}}{V_{2 d o f}} \times 100
\end{aligned}
$$

For example, equation 9 determines the maximum impact severity value over one engine cycle, i.e.

$$
\% \Delta \ddot{e}_{b, \max }=\left.\frac{\left[\max \left(\ddot{e}_{b, 3 \text { dof }}\right)-\max \left(\ddot{e}_{b, 2 \text { dof }}\right)\right]}{\max \left(\ddot{e}_{b, 2 \text { dof }}\right)}\right|_{720^{\circ}} \times 100
$$

\section{Optimisation procedure}

An optimisation procedure is essential to take into account the cumulative effect of the objective functions. The optimal NES specifications are determined for each NES mass ratio, separately. Conditions that lead to exacerbations in the 
objective functions are discarded from the analysis (negative values in equation 9). The optimal specifications for each mass ratio are selected by applying the following procedure.

- The priority of the objective functions is determined. Impact severity signifies the harshest (loudest) piston impact in one engine cycle through the eccentricity accelerations. Thus, this objective function has the highest priority. The reduction in the number of impacts is the second priority, since more impacts with mild severity are preferable to fewer impacts with significant harshness (from NVH perspective). The energy transfer function (last criterion) indicates the total energy in the impacted structure during one engine cycle. This criterion does not track the instantaneous energy variations but it ensures that the total energy content does not increase in the NES presence.

- Design specifications with the largest improvement in impact severity function are initially identified. The improvement for these combinations is distinguishably larger than the neighbouring designs (more than 50\%) and they are usually located at lower damping coefficients.

- Amongst the selected combinations, the specifications with the largest improvement in the number of impacts are then selected as optimal. Provided multiple options are available, the energy transfer function will be examined in the next stage.

- If multiple scenarios have the same improvement in energy levels, the specifications with the lowest damping coefficient are selected for the NES mechanism.

\section{Power loss evaluation}

The optimal specifications are determined for each NES mass ratio using the performance objective functions. The power loss is calculated for the above to ensure that the addition of absorbers does not deteriorate the frictional behaviour of the system (in comparison with the losses noted using conventional methods). The cycle-averaged power loss $\left(P_{L, m}\right)$ is estimated using equation 10 . The instantaneous power loss $\left(P_{L}\right)$ varies with friction force $\left(F_{f}\right)$ and sliding velocity $(\dot{x})$ at the piston-cylinder conjunction [39, 40].

$P_{L, m}=\frac{1}{2 \pi} \int_{0}^{2 \pi} P_{L}(\theta) d \theta, \quad P_{L}(\theta)=F_{f} \dot{x}$

Although the effect of viscous friction on the impact force is trivial, its contribution to power loss cannot be neglected. The contact forces in the 'dry' piston dynamics model are exploited to estimate the regime of lubrication and friction force. 
The contact loads at each side of the cylinder liner (TS and ATS) are known from equation 3 . The normal load at each side is calculated using equation (11).

$W_{T S}=F_{H, A}+F_{H, C}, \quad W_{A T S}=F_{H, B}+F_{H, D}$

The minimum film thickness during elasto-hydrodynamic lubrication is estimated using equation (12) [41]. $\alpha$ is the piezoviscous constant and $L$ is the contact length. $\eta_{o}, R$ and $E_{r}$ are the viscosity at atmospheric pressure, the equivalent radius of curvature of the contacting bodies and the modified modulus of elasticity $\left(E_{r}=\pi E\right.$ ), respectively. The transition from hydrodynamic to elasto-hydrodynamic lubrication is determined by the film thickness and the average height of surface asperities $\sigma$ (Equation 13).

$h_{m}=1.654 \frac{\left(\eta_{o} \dot{x}\right)^{0.7} R^{0.43} \alpha^{0.54} L^{0.13}}{E_{r}^{0.03} W}$

$\Lambda=h_{m} / \sigma$

For $\Lambda \geq 3$, the regime of lubrication is hydrodynamic and viscous friction is the only source of loss (Equation 14). The variation of viscosity with contact pressure $(P)$ is given by $\eta=\eta_{o} \exp (\alpha P)$. $A$ is the area of piston skirt. If $\Lambda<3$, mixed regime of lubrications prevails and both lubricant and asperities contribute to friction loss. The boundary friction (asperity effect) is indicated by $F_{b}$ (Equation 15$) . \tau_{e}$ is the Eyring stress $(\tau \approx 2 M P a)$ and $C_{p b} \approx 0.17[42,43]$.

$F_{v}=\eta \frac{\dot{x}}{h_{m}} A$

$F_{b}=\tau_{e} A_{a}+C_{p b} P_{a}$

$A_{a}$ and $P_{a}$ are the asperities' real contact area and contact pressure respectively, as defined through equations 16 and 17:

$A_{a}=\pi^{2}(\gamma \beta \sigma) A_{h} F_{2}(\Lambda)$

$P_{a}=\frac{8 \sqrt{2}}{15} \pi\left(\gamma_{a} \beta \sigma\right)^{2} \sqrt{\sigma / \beta} E A_{h} F_{\frac{5}{2}}(\Lambda)$

The group $\left(\gamma_{a} \beta \sigma\right)$ is suggested to be reasonably constant [44]. This group and $(\sigma / \beta)$ equal 0.055 and 0.001 for a camtappet contact with Gaussian distribution of the asperity heights and constant radius of curvature of the asperity tips [43, 45]. $A_{h}$ is the Hertzian contact area for the normal loads. $F_{2}$ and $F_{5 / 2}$ are statistical functions and they are estimated by their polynomial fits (Eqs.18-19) [46].

$F_{2}(\Lambda)=-0.0018 \Lambda^{5}+0.0281 \Lambda^{4}-0.1728 \Lambda^{3}+0.525 \Lambda^{2}-0.8043 \Lambda+0.5003$
$F_{5 / 2}(\Lambda)=-0.0046 \Lambda^{5}+0.0574 \Lambda^{4}-0.295 \Lambda^{3}+0.7844 \Lambda^{2}-1.0776 \Lambda+0.6167$ 
Provided the film thickness is very thin at the asperities tip and viscous shear stress exceeds Eyring stress $\left(\tau_{e}\right)$, the lubricant behaves like non-Newtonian fluid. The viscous friction force for non-Newtonian fluid is calculated in equation 20. The parameter $\gamma_{s}$ is approximated by $\dot{x} / 2$.

$F_{v N}=F_{v}+\gamma_{s}\left(\frac{P-P_{a}}{A_{h}}\right) A$

The summation of viscous and boundary friction constitutes the total friction force $\left(F_{f}=F_{v}+F_{b}\right)$.

\section{Results and discussion}

Parametric study

The objective functions are parametrically studied using contour plots (Figures 5-10). Results for the central case with $12.5 \%$ NES mass ratio are shown and contour plots for additional NES mass ratios are presented when clarification is required.

The impact severity objective function is illustrated for 7.5\% NES mass ratio (Figure 5). The labels 'max' and 'min' represent the maximum and minimum eccentricity accelerations. Areas of improved behaviour are shown at the top and bottom of the piston skirt. This NES design is effective for damping ratios between 0.005 and $0.01 \mathrm{Nms} / \mathrm{rad}$. The optimal stiffness coefficient is located between 20 and $50 \mathrm{Nm} / \mathrm{rad}^{3}$ for $d^{2} e_{t, \max }$. The area of improved performance appears at very low stiffness coefficients for $d^{2} e_{b, \min }$. A similar study is carried out for $12.5 \%$ NES mass ratio (Figure 6). The effective damping coefficients are spread over wider areas $(0.01$ to $0.02 \mathrm{Nms} / \mathrm{rad})$. Larger NES mass ratios produce greater improvements in impact severity (up to $40 \%$ for $d^{2} e_{b, \max }$ ). This area of improvement is between 0.01 and 0.04 Nms $/ \mathrm{rad}$ for $20 \%$ NES mass ratio (Figure 7). In all scenarios, the area of deteriorating behaviour partially overlaps the area of improvement. The optimal locations will be extracted later during the optimisation analysis. 

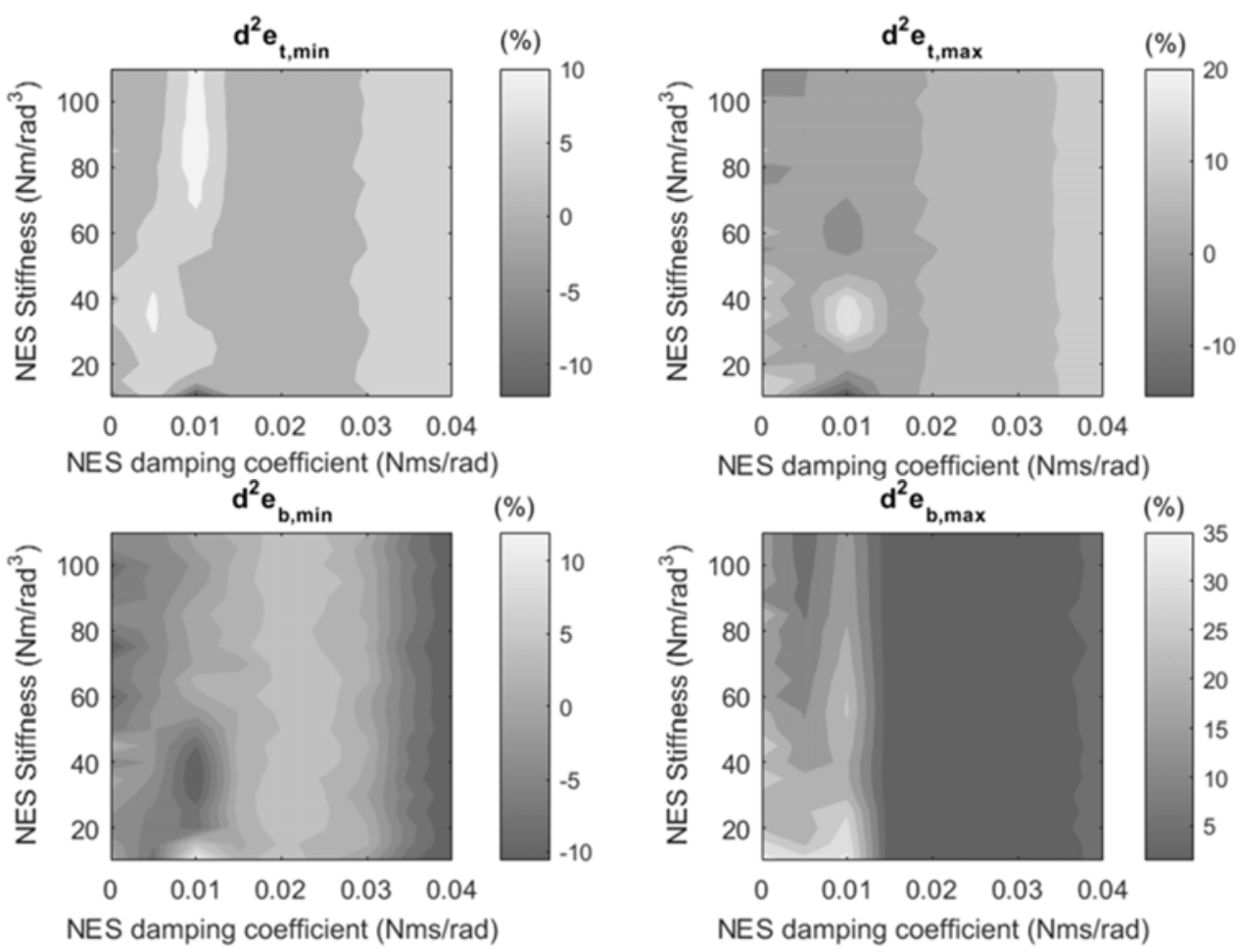

Figure 5: Impact severity objective function variation with damping coefficient $c_{t}$ and stiffness coefficient $k_{t}(\varepsilon=7.5 \%)$
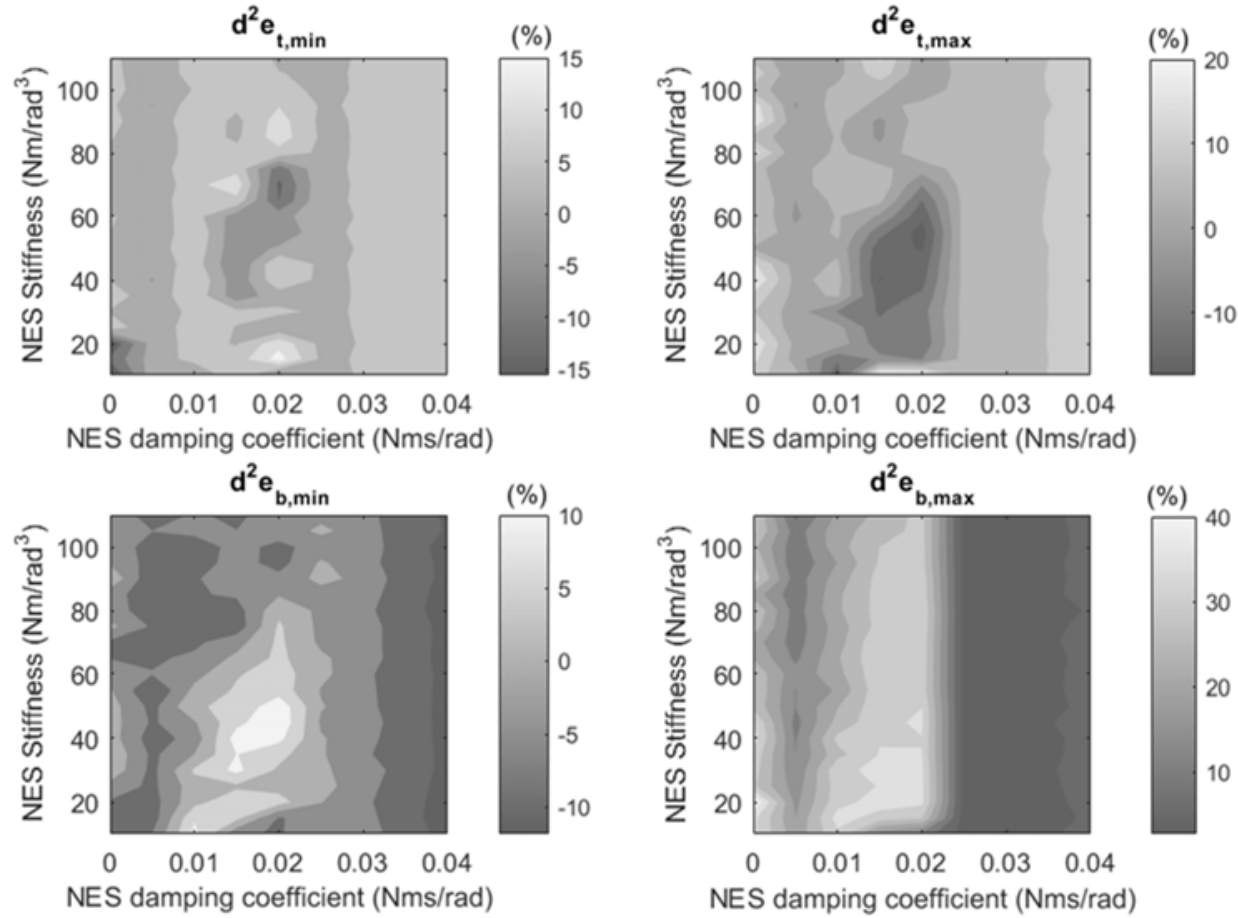

Figure 6: Impact severity objective function variation with damping coefficient $c_{t}$ and stiffness coefficient $k_{t}(\varepsilon=12.5 \%)$ 

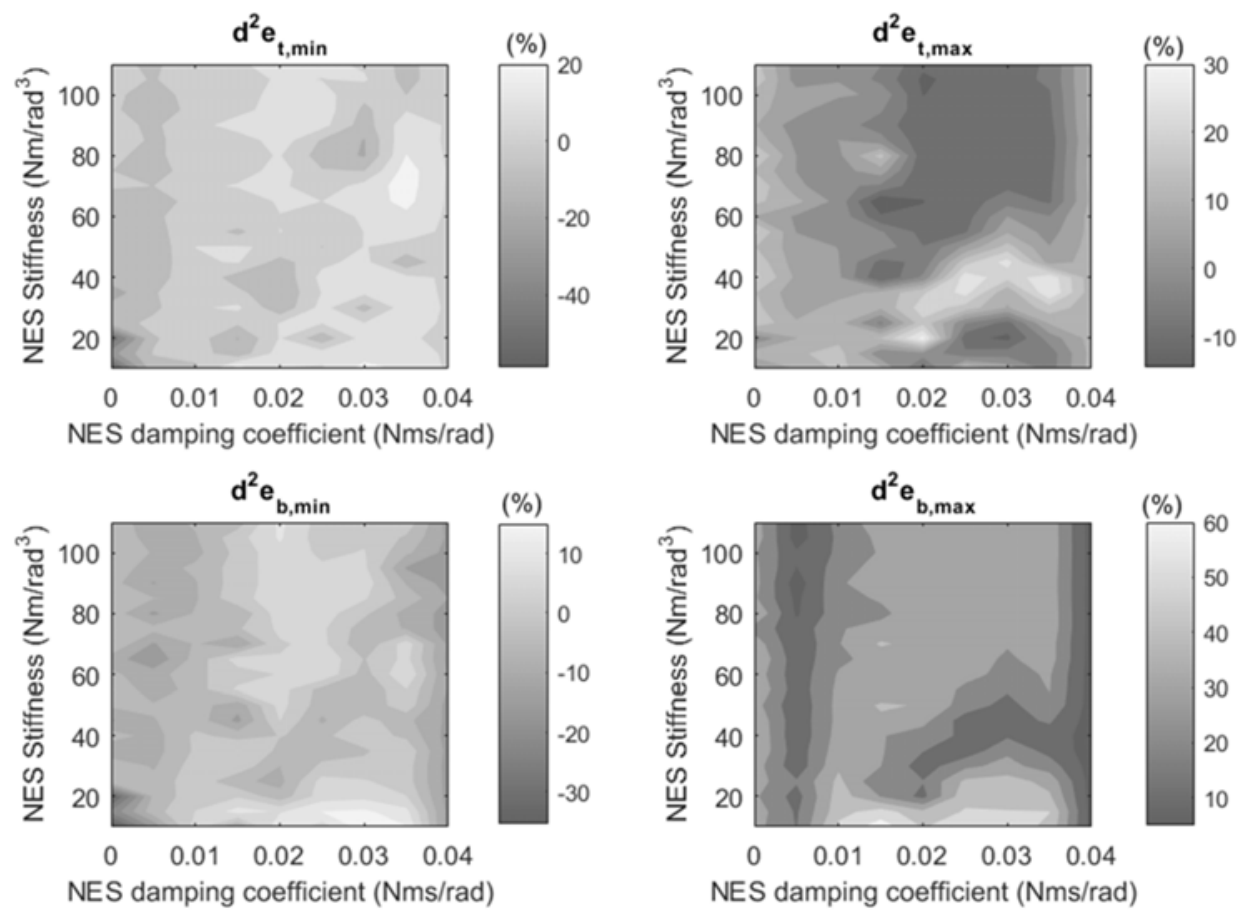

Figure 7: Impact severity objective function variation with damping coefficient $c_{t}$ and stiffness coefficient $k_{t}(\varepsilon=20 \%)$

The number of impacts (NoI) criterion is similarly studied using contour plots. The NoI for $7.5 \%$ NES mass ratio is shown in figure 8. The areas of improved performance are restricted between damping coefficient values of 0.005 and 0.015 $\mathrm{Nms} / \mathrm{rad}$ (similarly to the severity objective function). This area is stretched over a wider range of stiffness coefficients for the bottom eccentricity. The area of improvement is located between 0.01 and $0.025 \mathrm{Nms} / \mathrm{rad}$ for $12.5 \%$ NES mass ratio (Figure 9). The overlap between areas of improved and deteriorating behaviour is larger for stiffness coefficient values less than $40 \mathrm{Nm} / \mathrm{rad}^{3}$ at the bottom eccentricity. The scenario for $20 \% \mathrm{NES}$ mass ratio is not illustrated for brevity of the discussion. Regardless of the overlapping regions, the number of impacts can improve about 30 - $50 \%$ as the NES mass ratio varies between $7.5 \%$ and $20 \%$. The effect of overlapping is detailed during the optimisation analysis.

The energy transfer function ensures that the NES does not increase the energy content of the impacted structure during one engine cycle (refer to equations 8 and 9). Figure 10 shows the energy transfer criterion for $12.5 \%$ NES mass ratio. Zero damping exhibits severely deteriorating behaviour. Generally, there is improvement up to $10 \%$ at the thrust side and negligible improvement at the anti-thrust side of the cylinder bore. The areas of improved behaviour generally shift towards higher damping coefficients as the NES mass ratio increases (similarly to the other objective functions). 


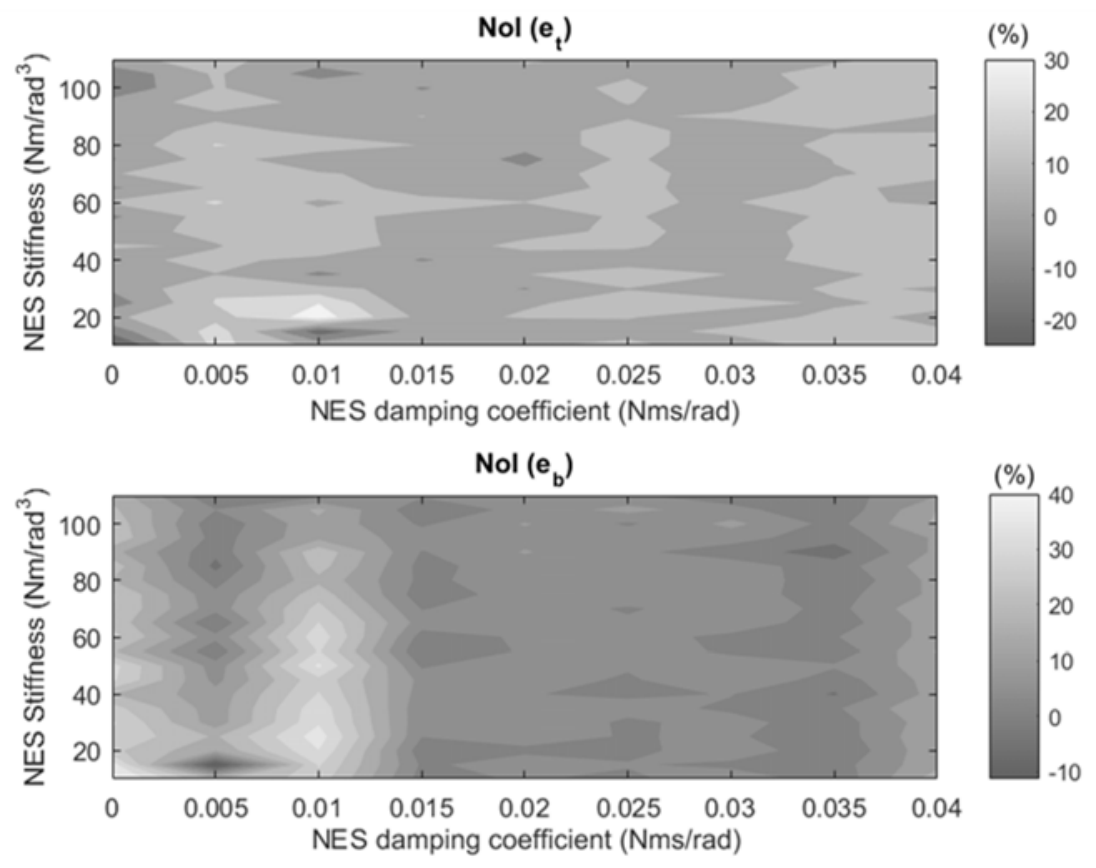

Figure 8: NoI objective function variation with damping coefficient $c_{t}$ and stiffness coefficient $k_{t}(\varepsilon=7.5 \%)$

\section{Selection of optimal designs}

The parametric study through contour plots shows the generic trends in the objective functions. Overlapping between areas of improved and deteriorating behaviour is estimated. However, the various objective functions are not interconnected using this approach. The optimisation procedure correlates the objective functions and finds the optimal design. The contour plots include the outputs of 189 simulations for each NES mass ratio. The combinations that lead to deteriorating behaviour in equation 10 (negative values) are initially removed. 84 and 12 combinations satisfy the criterion for all the objective functions using $7.5 \%$ and $12.5 \%$ NES mass ratios, respectively. 


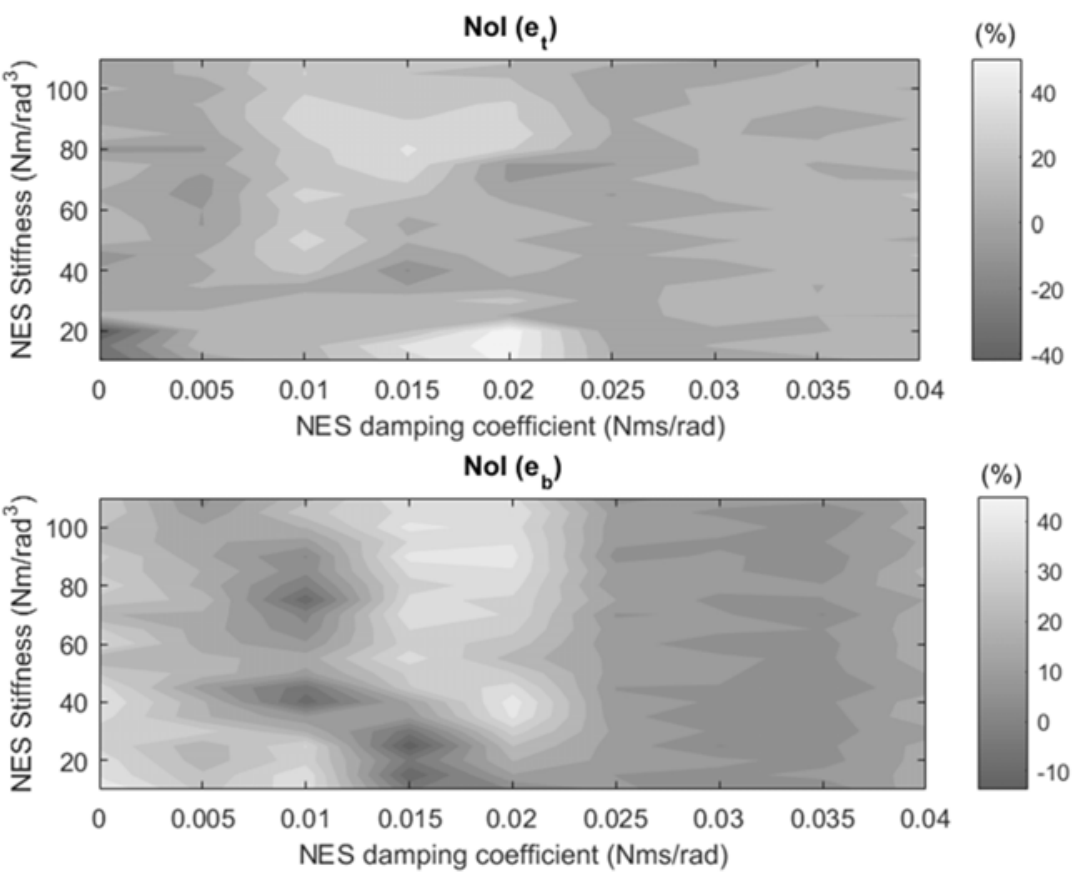

Figure 9: NoI objective function variation with damping coefficient $c_{t}$ and stiffness coefficient $k_{t}(\varepsilon=12.5 \%)$
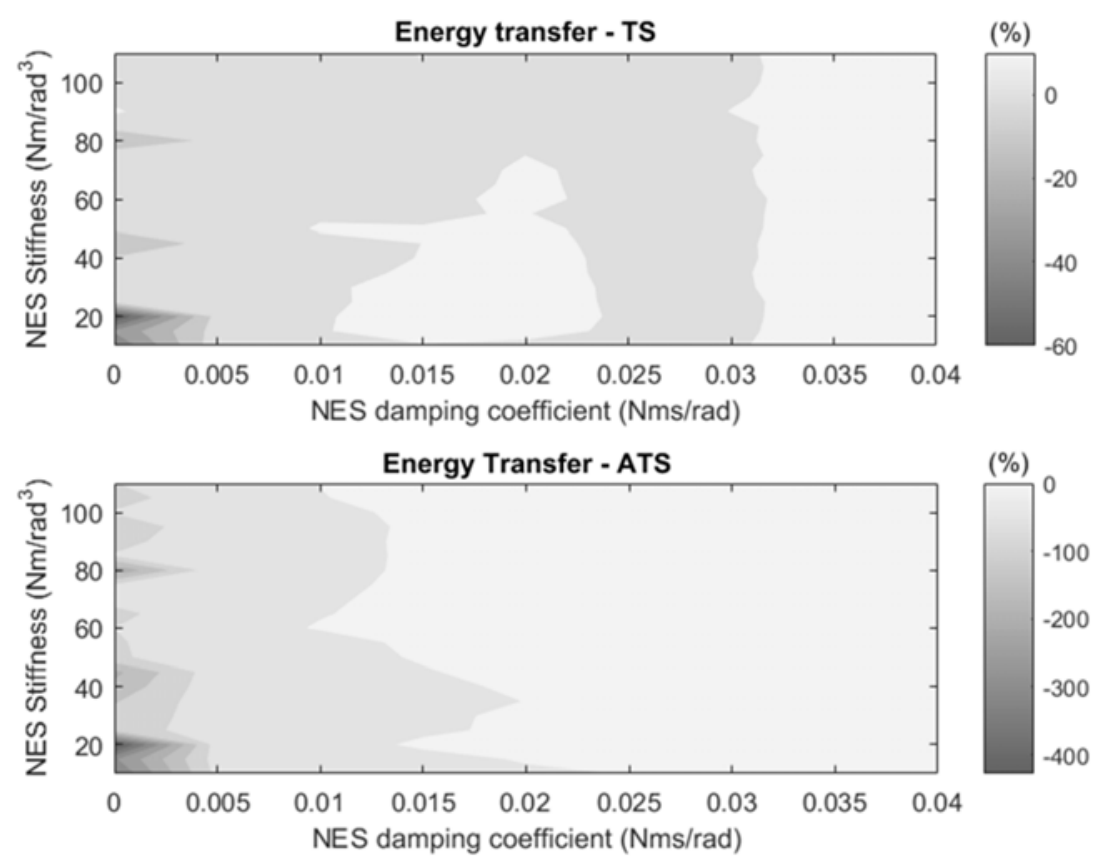

Figure 10: Transferred energy objective function variation with damping coefficient $c_{t}$ and stiffness coefficient $k_{t}(\varepsilon=$ $12.5 \%)$ 
The optimization procedure is applied to the remaining combinations. The outputs of the impact severity objective function are rearranged in an ascending order using the damping and stiffness coefficients of the NES (Figure 11). The horizontal axis specifies the position of each combination in the ascending sequence (an integer). Each integer corresponds to a specific damping-stiffness combination. The graph forms step-like jumps along the horizontal axis. The discrete jumps along the horizontal axis indicate the jump into the next damping coefficient value and the flat sections per damping coefficient value represent the variation of stiffness coefficient. This trend shows that the NES system is mainly driven by stiffness properties at very low damping coefficients. In the following graphs, the maximum $(m x)$ and minimum $(m n)$ states of the eccentricity accelerations are shown for the piston top $\left(e_{t}\right)$ and bottom $\left(e_{b}\right)$ lands. The eccentricity accelerations are largely improved at lower NES damping coefficients $(0.01 \mathrm{Nms} / \mathrm{rad}$ for $7.5 \%$ and $0.015-0.02 \mathrm{Nms} /$ rad for $12.5 \%$ NES mass ratios). The largest improvement takes place at $\ddot{e}_{b, m x}$ for both cases. The percentage of improvement drops to very small values and it gradually rises as the damping coefficient (integer number) increases. Thus, weaker damping allows for better communication of the NES with the piston. The NES capability in reducing impact severity improves from 20 to $35 \%$ as the NES mass ratio increases. The first four and two combinations are placed in the optimal design population for $7.5 \%$ and $12.5 \%$ NES mass ratios, successively. 

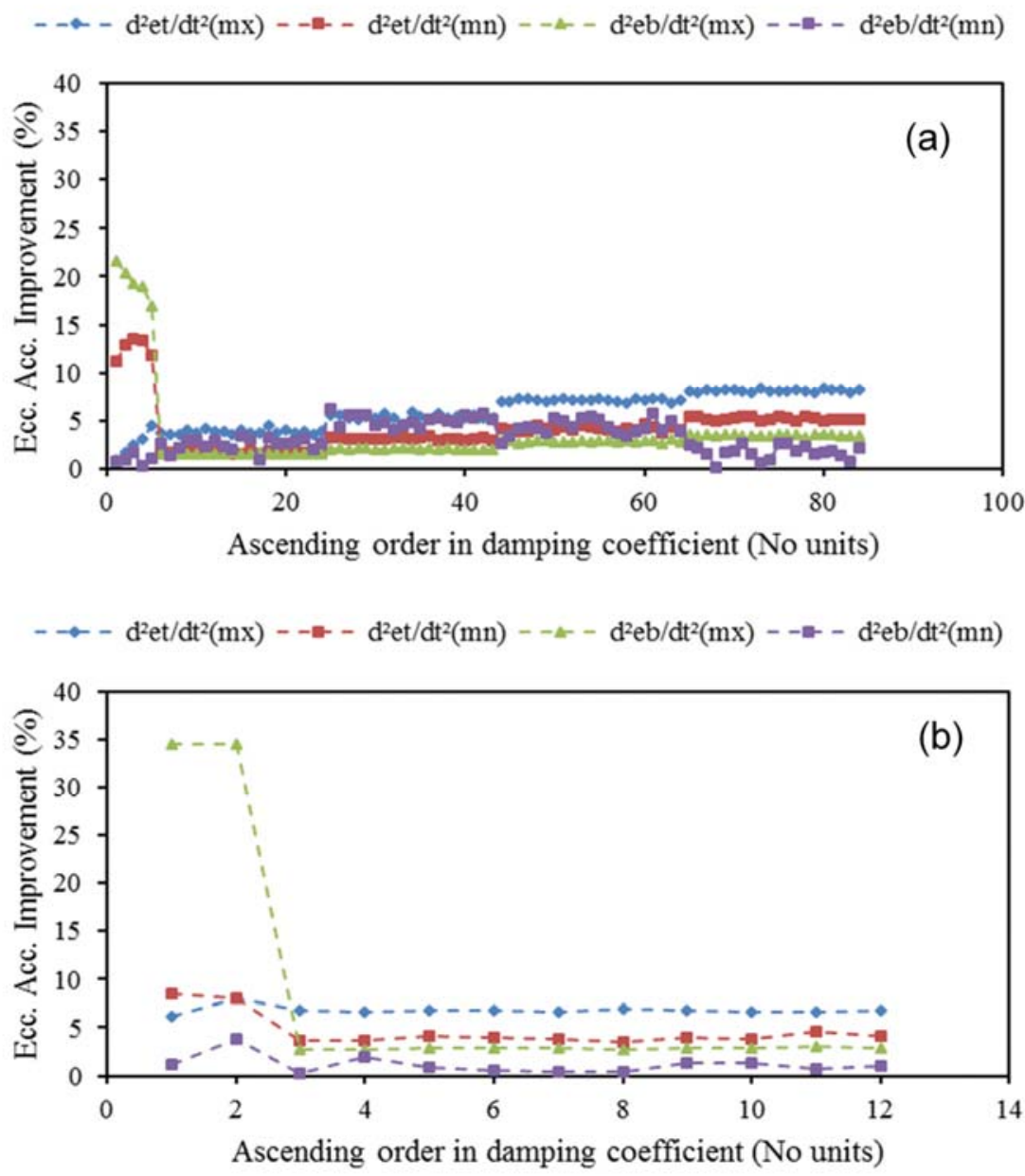

Figure 11: Eccentricity acceleration variation with damping coefficient for (a) $7.5 \%$ and (b) $12.5 \%$ NES mass ratios (maximum $(m x)$ and minimum $(m n)$ values at the piston top $\left(e_{t}\right)$ and bottom $\left(e_{b}\right)$ lands)

The number of impacts (NoI) and energy transfer objective functions should be analysed, since different designs specifications are included in the population (Figure 12). The horizontal axis shows the integer number with similar ascending sequence. The NoI is largely improved for lower damping coefficient values. This improvement is more evident at the bottom eccentricity $\left(\mathrm{NoI}\left(e_{b}\right)\right)$ in both cases. The NoI improves by $15 \%$ as the NES mass ratio increases from 7.5 to 12.5\%. Figure 13 shows the energy transfer functions for the thrust and anti-thrust sides of the cylinder liner (Etts and Etats). The energy transfer function improves up to 9 and $14 \%$ for 7.5 and $12.5 \%$ NES mass ratios, successively. 

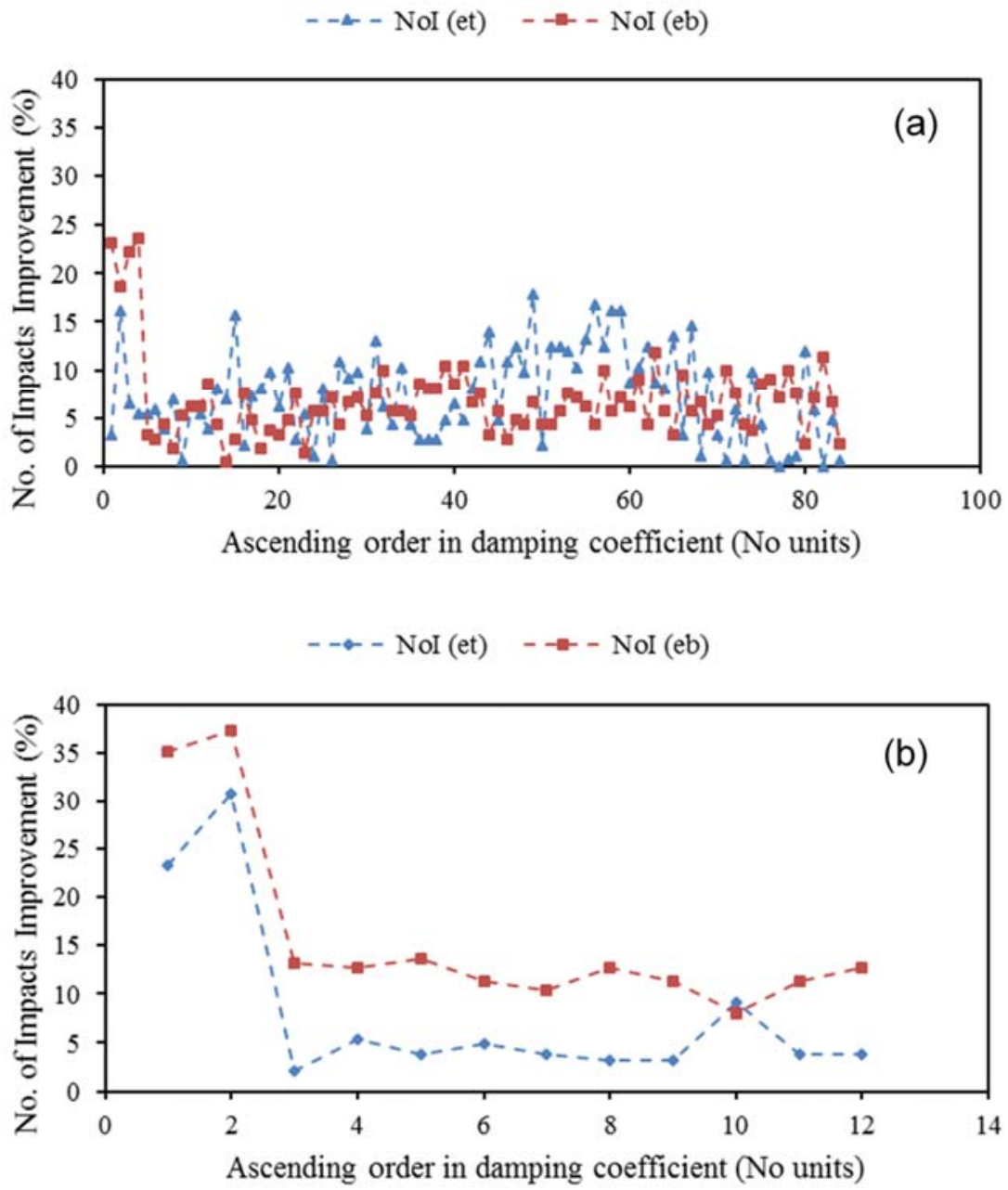

Figure 12: NoI variation with damping coefficient for (a) 7.5\% and (b) 12.5\% NES mass ratios at the top $\left(e_{t}\right)$ and bottom $\left(e_{b}\right)$ of the piston skirt 

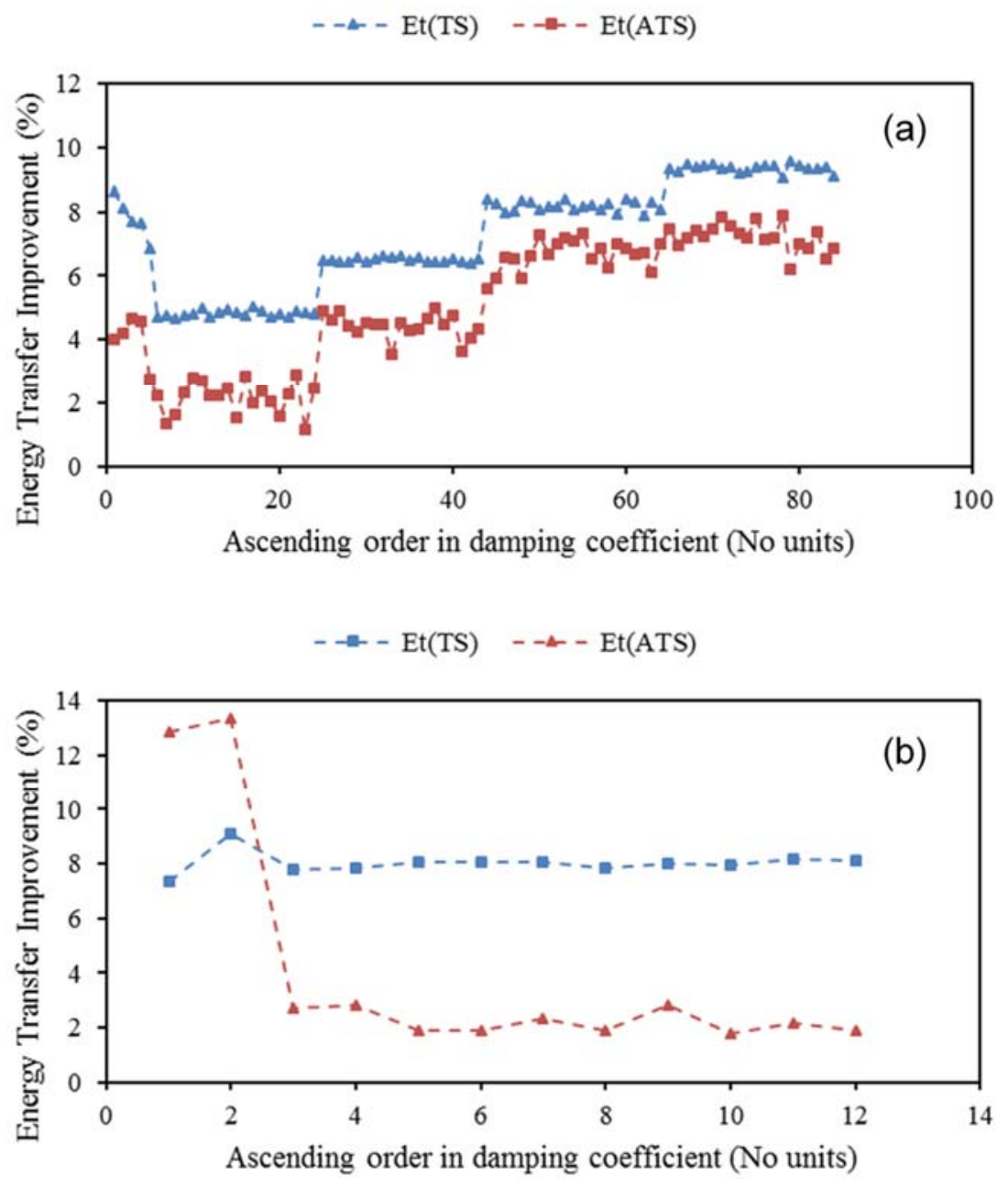

Figure 13: Transferred energy variation with damping coefficient at (a) 7.5\% and (b) 12.5\% NES mass ratio (at TS and ATS of the cylinder liner)

The NES operates effectively at lower damping coefficient values. Thus, the population of parametric simulations within this region is investigated for the optimal NES design. Only two combinations are available for $12.5 \%$ NES mass ratio, shown with integer values 1 and 2 throughout figures 11-13. The second combination $\left(\varepsilon=12.5 \%, c_{t}=0.02 \mathrm{Nms} / \mathrm{rad}\right.$ and $k_{t}=80 \mathrm{Nm} / \mathrm{rad}^{3}$ ) presents the largest improvement in all objective functions. The first four combinations (integers 1 to 4) for the 7.5\% NES mass ratio also belong to the selected population for optimum specifications. The impact severity and energy transfer functions deviate up to $5 \%$ across these combinations. The second combination $\left(\varepsilon=7.5 \%, c_{t}=\right.$ $0.01 \mathrm{Nms} / \mathrm{rad}$ and $\left.k_{t}=80 \mathrm{Nm} / \mathrm{rad}^{3}\right)$ experiences the largest improvement in the NoI at the piston bottom land $(\sim 15 \%)$. Similar analyses are carried out for other NES mass ratios. The optimal design specifications for each NES mass ratio are

S. Theodossiades, CND-17-1339 
shown in Table 1. The optimal designs have higher damping coefficients as the NES mass ratio increases. None of the stiffness-damping combinations can lead to simultaneous improvement of the objective functions for $15 \%$ mass ratio. The performance of these designs is compared in terms of their dynamics response (Figure 14). The horizontal axis shows the objective functions and the vertical axis signifies the percentage of improvement for each function. The optimal designs with $12.5 \%$ and $20 \%$ mass ratios show better performance in terms of impact severity (eccentricity accelerations). The NES design with $17.5 \%$ mass ratio is largely improved in terms of NoI at the piston top land $\left(\operatorname{NoI}\left(e_{t}\right)\right)$. The NoI function improves at the piston's top and bottom lands for $12.5 \%$ and $20 \%$ NES mass ratios, whereas considerable improvement is evident only at the top land for $17.5 \%$ mass ratio. The energy transfer function generally has better performance for $20 \%$ NES mass ratio. Each objective function comprises multiple values with a few being optimal. Thus, the average value for each function indicates its overall performance (Table 2). The best dynamic response is achieved using 20\% NES mass ratio. The next optimal NES design specifications are for $12.5 \%$ and $17.5 \%$ mass ratios, successively. The NES with $10 \%$ and 7.5\% mass ratios show moderate dynamic performance, whereas the $5 \%$ NES mass ratio exhibits the minimum improvement. The NES performance in terms of power loss will be discussed hereafter.

Table 1. The optimal NES design specifications for each NES mass ratio

\begin{tabular}{|c|c|c|c|c|c|c|c|}
\hline$\varepsilon(\%)$ & 5 & 7.5 & 10 & 12.5 & 15 & 17.5 & 20 \\
\hline$k_{t}\left(\mathrm{Nm} / \mathrm{rad}^{3}\right)$ & 20 & 80 & 105 & 80 & NA & 40 & 60 \\
\hline$c_{t}($ N.m. s/rad $)$ & 0.005 & 0.01 & 0.01 & 0.02 & NA & 0.025 & 0.035 \\
\hline
\end{tabular}

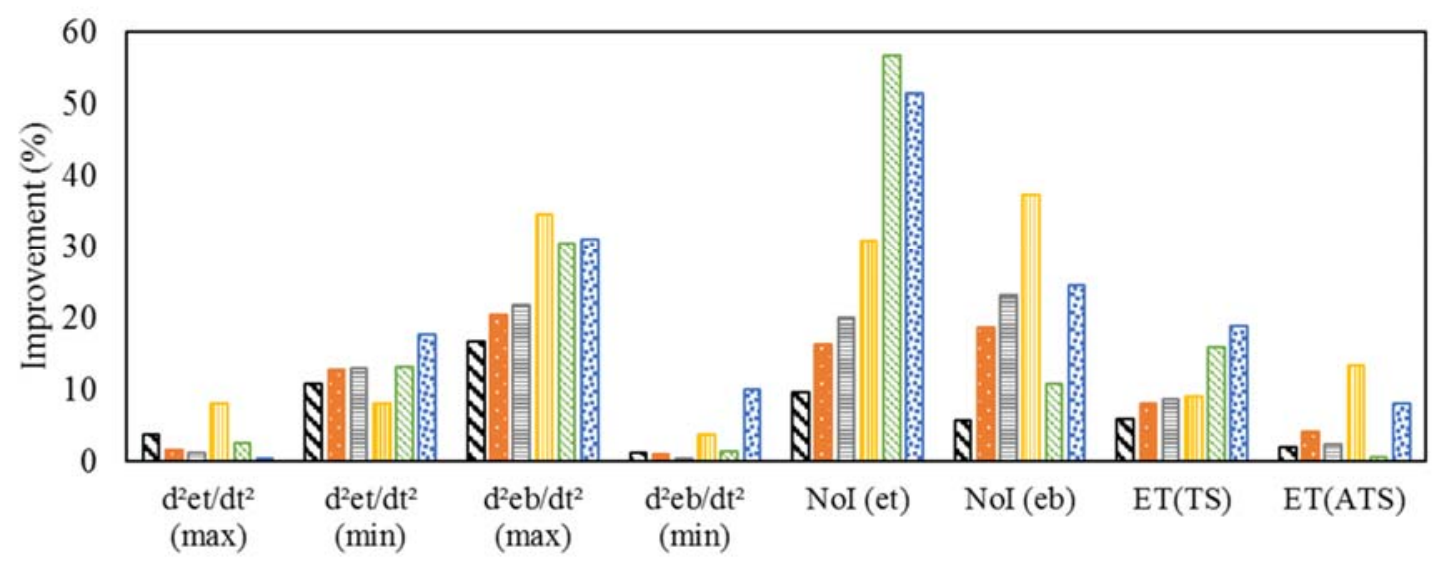

S. Theodossiades, CND-17-1339 
Figure 14. Comparison of performance improvement for different objective functions and NES design specifications

Table 2. The average values of the objective functions for optimal NES designs

\begin{tabular}{c|cccccc}
$\boldsymbol{\varepsilon}(\%)$ & $\mathbf{5}$ & $\mathbf{7 . 5}$ & $\mathbf{1 0}$ & $\mathbf{1 2 . 5}$ & $\mathbf{1 7 . 5}$ & $\mathbf{2 0}$ \\
\hline Impact severity (\%) & 8.11 & 8.98 & 9.14 & 13.60 & 11.89 & 14.77 \\
NoI (\%) & 7.69 & 17.42 & 21.55 & 34.03 & 33.80 & 37.94 \\
Energy transfer (\%) & 3.94 & 6.15 & 5.57 & 11.20 & 8.29 & 13.50
\end{tabular}

\section{Time history and power loss analyses}

The NES performance analysis continues using two sets of results: (i) piston impact dynamics through the kinematics time history and (ii) power losses at the piston-cylinder conjunction. The simulations are run for 60 engine cycles to prove the NES stable performance. Only the last three cycles are presented herein.

The piston eccentricity displacements are illustrated in figure 15 for the design with $20 \%$ mass ratio. This information is exploited to predict the number of impacts. The horizontal axis shows the crank angle. The piston eccentricities without NES (2-DOF model) are compared with the eccentricities for a piston equipped with NES (3-DOF model). Two piston impacts are eliminated at the top eccentricity during the intake stroke (C labels). Transient impacts are initiated by short separation of the piston from the cylinder liner due to transient oscillations at the piston-cylinder conjunction. These impacts are present towards the top dead centre of the exhaust stroke (B labels) in the 2-DOF model. The NES attachment considerably mitigates these transient oscillations at the top eccentricity. Similar oscillations are present after the main impact at the beginning of the compression stroke (A labels). These oscillations are remarkably reduced at the bottom eccentricity $\left(e_{b}\right)$ for the 3-DOF model. The transient impacts at the bottom eccentricity are also improved during the first half of the intake stroke (E labels). One transient impact appears in the middle of the compression stroke (D labels). Generally, the eccentricity displacements are improved in the presence of NES (3-DOF model). 

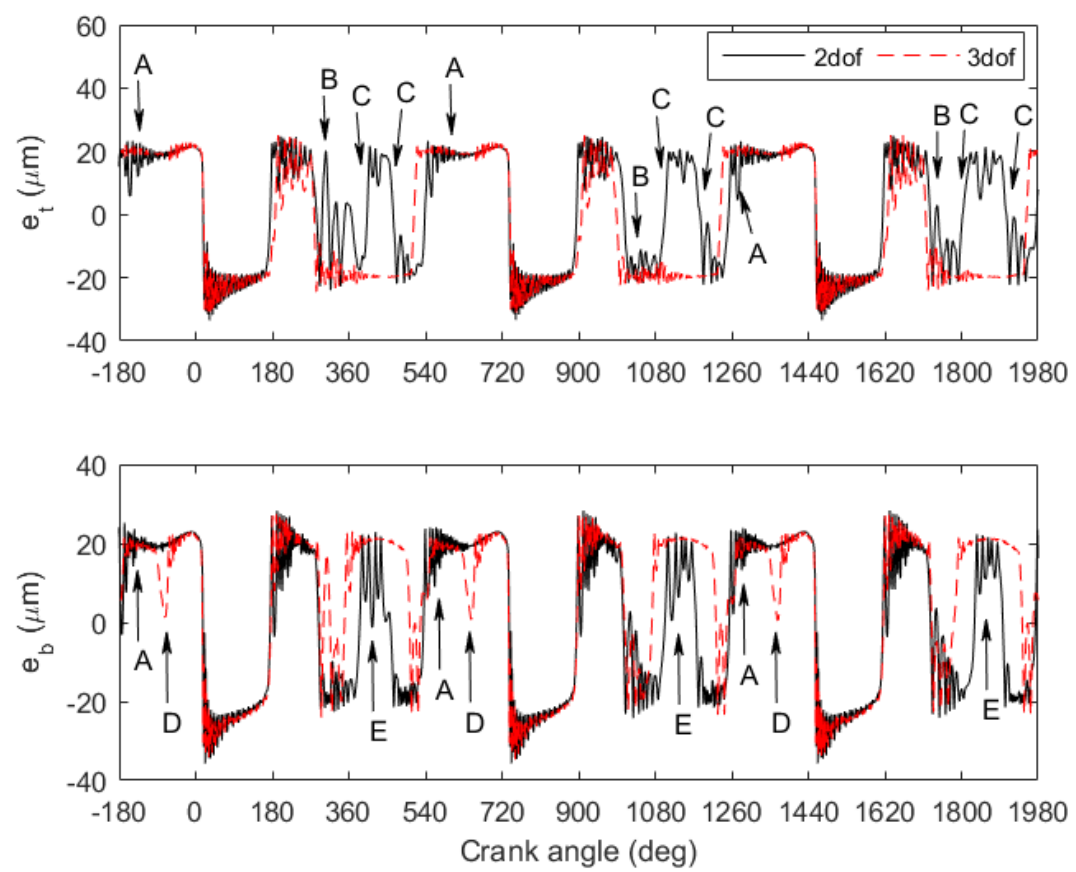

Figure 15: Eccentricity displacements for three engine cycles (2-DOF model (black) vs. 3-DOF model (red))

The eccentricity accelerations are shown in figure 16 for the 2-DOF and 3-DOF models, where the behaviour is generally improved for the piston equipped with NES. The acceleration during combustion stroke $\left(0\right.$ to $\left.180^{\circ}\right)$ is significant, producing the largest piston impact. The NES action reduces those oscillations at both eccentricities, whereas improvements at the bottom eccentricity are noticeably larger. Further improvements are observed in the proximity of the top and bottom dead centres $\left(0^{\circ}, 180^{\circ}, 540^{\circ}\right.$ etc.). The NES alters the rotational motion in these locations, such that the eccentricity acceleration is reduced. 

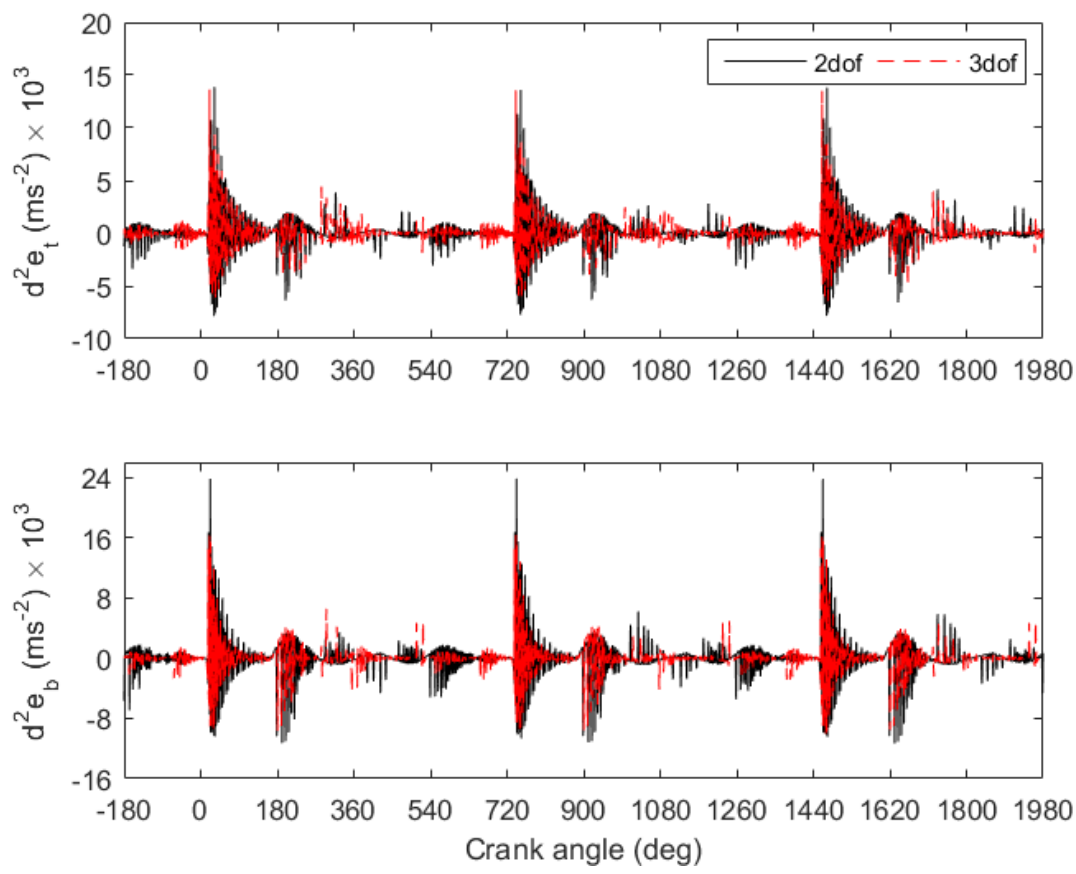

Figure 16: Eccentricity accelerations for three engine cycles (2-DOF model (black) vs. 3-DOF model (red))

Figures 17 and 18 illustrate the instantaneous power losses for the piston equipped with $12.5 \%$ and $20 \%$ mass ratios NES, respectively. Power loss improves at the beginning of the compression stroke as the NES mass ratio increases from $12.5 \%$ to $20 \%\left(-180^{\circ}, 540^{\circ}\right.$ and $1260^{\circ}$ crank angle). The maximum power loss occurs during the combustion stroke. The NES attachment cannot alleviate the losses at this part of the engine cycle (e.g. 0 to $180^{\circ}$ ). The piston undergoes rotational motion during the intake stroke (e.g. 360 to $540^{\circ}$ ). The piston tilt increases the contact duration with the cylinder liner, leading to increase in the power losses at this part of the engine cycle. The magnitude of this rise is proportional to the NES mass ratio. Power loss improves at some parts of the engine cycle, whilst it exacerbates at other parts. Thus, the cycle-averaged power loss is a good estimation for the overall performance of the NES (Equation 10). The primary system (2-DOF model) loses an average power of $107 \mathrm{~W}$ during one engine cycle. This parameter becomes $113 \mathrm{~W}$ and $119 \mathrm{~W}$, as the NES mass ratio increases from $12.5 \%$ to $20 \%$, indicating $6 \%$ and $12 \%$ increase in power losses. Similar calculations are carried out for other NES optimal design specifications (Figure 19). Despite the increase in power loss, the NES performance should be evaluated against conventional control methods of piston's secondary motion. One case study shows that $67 \%$ reduction in clearance size can lead to $158 \%$ increase in mean friction power loss at 4000 rpm engine speed [13]. At 1800 rpm engine speed, 60\% reduction in clearance size exacerbates the mean friction power loss by 5.88\% 
[12]. Offner [13] studied the effect of piston pin height on friction power losses. It was estimated that $60 \%$ increase in the pin height can exacerbate the power loss by $16.2 \%$. Nakayama [11] has shown that the effectiveness of crankshaft offset reduces at high engine speeds. However, the NES performance is proven to be robust with engine speed variations [47]. At 3500rpm, the power losses for $12.5 \%$ mass ratio NES are comparable to the losses at $1800 \mathrm{rpm}$ using clearance reduction methods. It must be noted though that NES with larger mass ratios are not efficient due to power losses and the smaller mass ratios are not effective, dynamically. Thus, this NES design can be appointed as an alternative method for the control of piston secondary motion, since the power loss performance is better than similar conventional control methods at higher engine speeds.

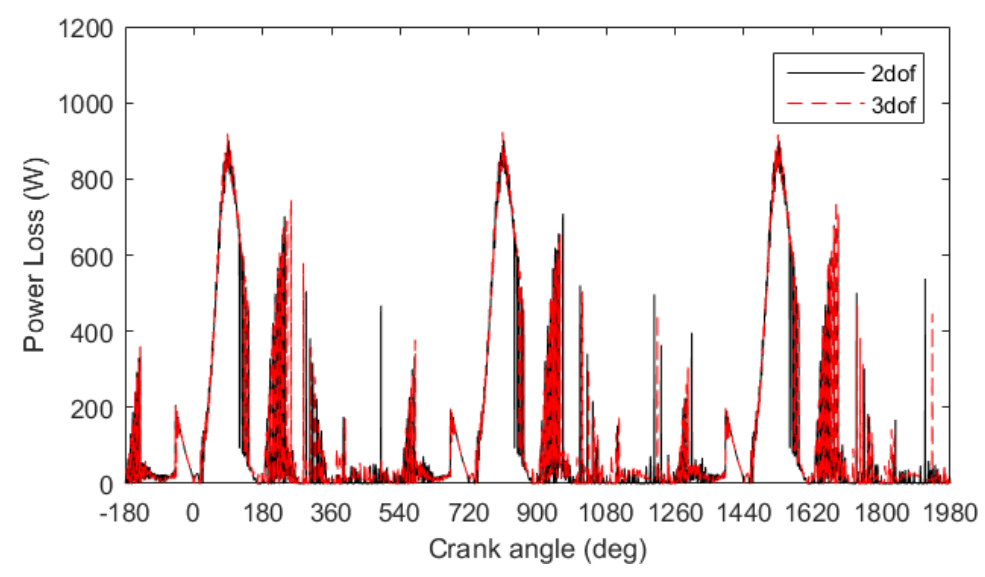

Figure 17: Power loss variations for the primary system (2-DOF model) and piston equipped with $12.5 \%$ mass ratio NES (3-DOF model)

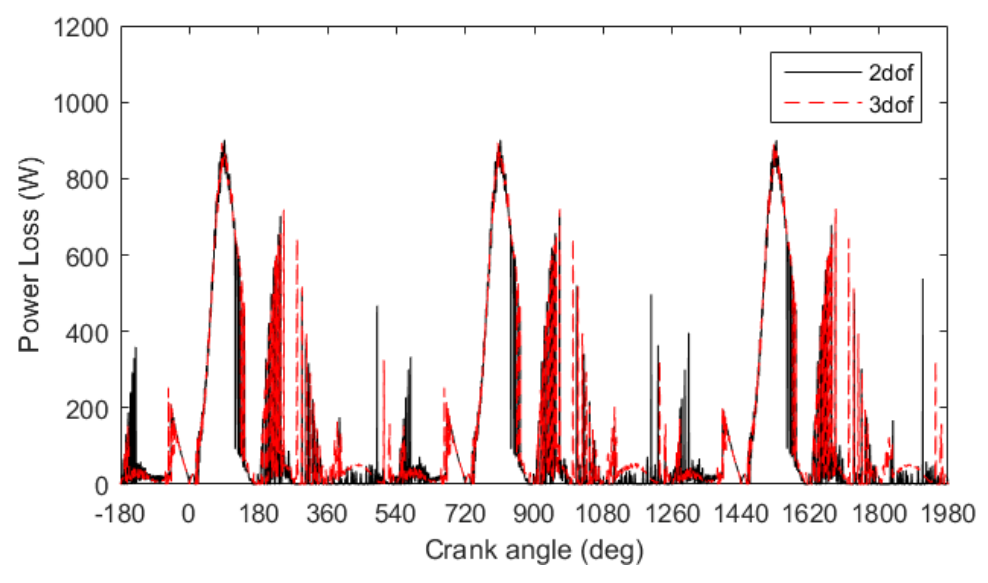

S. Theodossiades, CND-17-1339 
Figure 18: Power loss variations for the primary system (2-DOF model) and piston equipped with 20\% mass ratio NES (3DOF model)

The optimal NES design was selected through extensive numerical simulations, which confirm the improvement in the system's kinematics. However, these analyses do not provide information regarding the energy transfer mechanism between the piston and NES. Frequency-energy plots (FEP) have been produced to graphically represent the variation of nonlinear normal modes (NNMs) with respect to the energy content of the system [48]. NNMs are free periodic and synchronous oscillations of the undamped, unforced system [49] and they are numerically evaluated using a MATLAB code developed by Peeters et al [50]. The initiation of NNMs are predicted using linear normal modes (LNM) for low energy oscillations whereas the frequency content of oscillations is numerically computed for high energy oscillations using a predictor-corrector routine. The NNM backbones for grounded pendulum with $12.5 \%$ mass ratio are plotted in figure 20. Each backbone corresponds to NES with different restoring force coefficient. The energy-wavelet cloud of piston's secondary motion is overlaid on the FEP (Figure 20), in a similar way as in [48]. The relevant energy calculations are described in Appendix A. The wavelet energy cloud was examined for various engine speeds. For the brevity of discussion, only the scenario at 3500 rpm engine speed is presented. The NES works effectively in the frequency regions where the NNM backbones coincide with the energy-wavelet cloud of the system. A pendulum absorber without nonlinear restoring element shows ineffective energy transfer (Figure 20). Pendula with low nonlinear stiffness coefficient have high energy contents at low frequencies. The NNM backbone of the optimal pendulum design $\left(\varepsilon=12.5 \%\right.$ and $k_{t}=80$ $\mathrm{Nm} / \mathrm{rad}^{3}$ ) crosses the high-density region of the energy-wavelet cloud. This finding complies with the output of the optimisation analysis and shows effective energy transfer [48] between the piston and the pendulum absorber. 


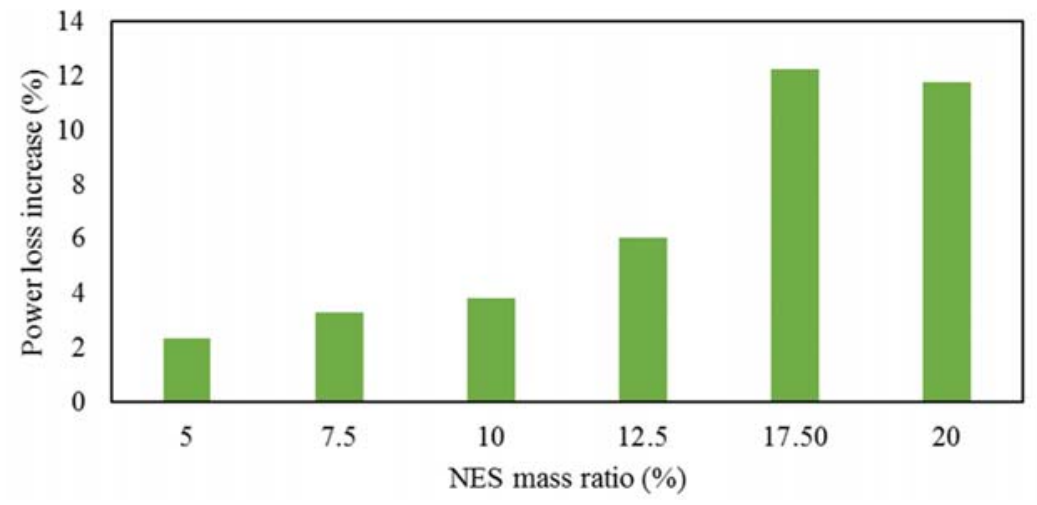

Figure 19: Power loss increase with respect to the primary system (without NES)

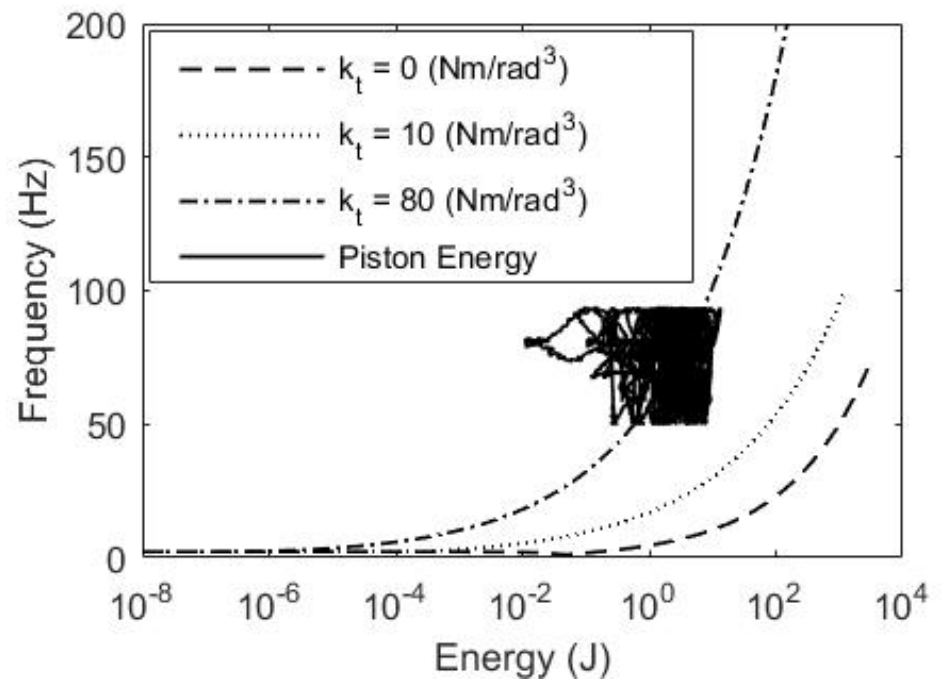

Figure 20: Frequency-energy plot of grounded pendulum and energy-wavelet cloud of the piston equipped with NES

$$
\text { (3500 rpm and } \varepsilon=12.5 \% \text { ) }
$$




\section{Conclusions}

The concept of targeted energy transfer is studied for reducing piston's secondary motion for the first time. This analysis comprises the nonlinear dynamics of the piston and the energy absorber. The dynamics model of piston's secondary motion is exploited to determine the optimum NES design specifications. A pendulum NES is effective in controlling piston rotation, since this motion's amplitude is one order of magnitude larger than piston translation. The NES design variables are optimised through a parametric study. Three objective functions are utilised to select the optimal designs for seven NES mass ratios. The effectiveness of pendulum NES in the control of piston impacts is confirmed. Power loss analysis is carried out taking into account losses through hydrodynamic, elasto-hydrodynamic and mixed regimes of lubrication. At the wide range of engine speed, the NES with $12.5 \%$ mass ratio can generate less power loss than the conventional methods. Thus, NES has a potential as an alternative method for controlling piston's secondary motion.

The current theoretical study shows that there is potential in controlling piston's secondary motion using NES. It should be emphasized that the NES pendulum design, as proposed, fits the purpose of a proof of concept study. From a practical perspective, the NES design should be tuned to the engine's packaging specifications. In present study, the NES is designed such that the pendulum does not impinge to the piston skirt and cylinder liner. Thus, its only energy transfer path is through the stiffness and damping. The NES interference with other engine components, e.g. crankshaft at the bottom dead centre, depends on the component dimensions. In experimental investigations, the proposed pendulum length should be readjusted to avoid such interferences, using standard IC engine design guidelines.

\section{Acknowledgments}

The authors wish to express their gratitude to the EPSRC for the financial support extended to the Encyclopaedic Program Grant (EP/G012334/1), under which this research was carried out. Thanks are also due to the consortium of industrial partners of the Encyclopaedic project, particularly to Capricorn Automotive in this instance.

Appendix A: Energy calculations for piston’s secondary motion

The energy content of the primary system comprises the kinetic energy due to the lateral translation and rotation of the piston: 
$K . E .=\frac{1}{2}\left[\left(m_{p i s}+m_{p i n}+m_{t}\right) \dot{e}_{p}^{2}+I_{p} \dot{\beta}^{2}+m_{t} L_{t}^{2} \dot{\gamma}^{2}\right]$

The restored energy in the cylinder liner is due to structural deformations. The pendulum restores energy through its nonlinear spring element. The potential energy due to these deformations is given as:

P.E. $=\frac{2}{5} k_{H} \delta^{5 / 2}+\frac{1}{4} k_{t}(\gamma-\beta)^{4}$

\section{References:}

[1] Rahnejat, H., 2000, “Multi-body dynamics: historical evolution and application,” Proc. Ins. Mech. Eng.: Part C, 214, pp. 149-173.

[2] Ouis, D., 2001, “Annoyance from road traffic noise: a review,” J. Environmental Psychology, 21, pp. 101-120, Academic Press, DOI: 10.1006/jevp.2000.0187.

[3] Gupta, S., 2002, "Elasto-multi-body dynamics of internal combustion engines with thin shell elastohydrodynamic journal bearings,” PhD Thesis, Loughborough University.

[4] Kanda, H., Okubo, M., and Yonezawa, T., 1990, "Analysis of noise sources and their transfer paths in diesel engines,” SAE International, SAE900014.

[5] Lalor, N., Grover, E.C., and Priede, T., 1980, "Engine noise due to mechanical impacts at pistons and bearings," SAE Technical Paper, SAE800402.

[6] Kaiser, H., Schmilien, K., Spessert, B., 1988, "Acoustical optimization of the piston slap by combination of computing and experiments,” SAE Technical paper, SAE 880100.

[7] Edara, R., 2008, “Reciprocating engine piston secondary motion - Literature review,” SAE Technical papers, SAE 2008-01-1045.

[8] Li, D.F., Rohde, S.M., and Ezzat, H.A., 1983, “An automotive piston lubrication model,” ASLE Trans., 26(2), pp. $151-160$.

[9] Haddad, S.D., and Tjan, K.T., 1995, “An analytical study of offset piston and crankshaft designs and the effect of oil film on piston slap excitation in a diesel engine,” Mech. Mach. Theory, 30(2), pp. 271-284.

[10] Nakashima, K., Yajima, Y., and Suzuki, K., 1999, “Approach to minimization of piston slap force for noise reduction - investigation of piston slap force by numerical simulation,” SAE of Japan, 20, pp. 211-216. 
[11] Nakayama, K., Tamaki, S., Miki, H., and Takiguchi, M., 2000, "The effect of crankshaft offset on piston friction force in a gasoline engine,” SAE technical paper, SAE2000-01-0922.

[12] Mansouri, S.H., and Wong, V.W., 2005, "Effects of piston design parameters on piston secondary motion and skirtliner friction,” Proc. Inst. Mech. Eng. Part J: J. Eng. Trib., 219, pp. 435-449.

[13] Offner, G., Lorenz, N., and Knaus, O., 2012, "Piston clearance optimization using thermos-elasto hydrodynamic simulation to reduce piston slap excitation and friction loss,” SAE International, SAE2012-01-1530.

[14] Kurt, M., Eriten, M., McFarland, D.M., Bergman, L.A., and Vakakis, A.F., 2014, "Frequency-energy plots of steady-state solutions for forced and damped systems, and vibration isolation by nonlinear mode localization,” Communication in Nonlinear Science and Numerical Simulation, 19, pp. 2905-2917.

[15] Gendelman, O., Manevitch, L.I., Vakakis, A.F., and M’Closkey, R., 2001, "Energy pumping in nonlinear mechanical oscillators: Part I: Dynamics of the underlying Hamiltonian systems,” J. App. Mech., 68, pp. 34-41.

[16] Vakakis, A.F., Manevitch, L.I., Gendelman, O., and Bergman, L., 2003, "Dynamics of linear discrete systems connected to local, essentially non-linear attachements,” J. Sound and Vibration, 264, pp. 559-577.

[17] Manevitch, L.I., Gourdon, E., Lamarque, C.H., 2007, “Towards the design of an optimal energetic sink in a strongly inhomogeneous two-degree-of-freedom system,” J. App. Mech., 74, pp. 1078-1086.

[18] Gendelman, O., 2008, "Transition of energy to a nonlinear localised model in a highly asymmetric system of two oscillators,” Nonlinear Dynamics, 25, pp. 237-253.

[19] Gendelman, O.V., and Starosvetsky, Y., 2008, "Quasi-periodic response regimes of linear oscillator coupled to nonlinear energy sink under periodic forcing,” J. App. Mech., 74, pp. 325-331.

[20] Dolatabadi, N., Theodossiades, S., and Rothberg, S.J., 2017, "Passive control of piston secondary motion using nonlinear energy absorbers,” J. Vibration and Acoustics, ASME transactions, 139(5), VIB-16-1462, DOI: 10.1115/1.4036468.

[21] Karayannis, I., Vakakis, A.F., Georgiades, F., 2008, “Vibro-impact attachments as shock absorbers,” Proc. Inst. Mech. Eng., Part C: J. Mech. Eng. Sci., 222, pp. 1899-1908.

[22] Lee, Y.S., Vakakis, A.F., Bergman, L.A., McFarland, D.M., Kerschen, G., 2007, “Suppressing aeroelastic instability using broadband passive targeted energy transfers, Part 1: Theory,” Journal of AIAA, 45(3), pp. 693-711. 
[23] Dolatabadi, N., Theodossiades, S., and Rothberg, S. J., 2015, “On the identification of piston slap events in internal combustion engines using tribodynamic analysis,” Mech. Sys. and Sig. Proc., 58-59, pp. 308-324.

[24] Dolatabadi, N., Littlefair, B., De-La-Cruz, M., Theodossiades, S., Rothberg, S. J., and Rahnejat, H., 2015, “A transient tribodynamic approach for the calculation of internal combustion engine piston slap noise,” J. Sound and Vibration, 352, pp. 192-209.

[25] Littlefair, B., De-La-Cruz, M., Theodossiades, S., Mills, R., Howell-Smith, S., Rahnejat, H., and Dwyer-Joyce, R., 2014, “Transient tribo-dynamics of thermos-elastic compliant high-performance piston skirts,” Trib. Lett., 53(1), pp. 51-70.

[26] Meng, X., Xie, Y., 2012, “A new numerical analysis for piston skirt-liner system lubrication considering the effects of connecting rod inertia,” Trib. Int., 47, pp. 235-243.

[27] Balakrishnan, S., 2002, “Transient elasto-hydrodynamic analysis of piston skirt lubricated contact under combined axial, lateral and tilting motion,” PhD Thesis, Loughborough Univeristy.

[28] Cho, J., and Jang, S., 2004, "Effects of skirt profiles on the piston secondary movements by the lubrication behaviour,” International J. Auto. Tech., 5(1), pp. 23-31.

[29] Goenka, P.K., Meernik, P.R., 1992, “Lubrication analysis of piston skirts,” SAE Technical papers, SAE 920490, pp. 77-86.

[30] Hertz, H., 1882, “Über die Berührung fester elastischer Körper (On the contact of elastic solids),” Journal für die reine und angewandte Mathematik, 92, pp.156-171. (For English translation see Miscellaneous Papers by H. Hertz, Eds. Jones and Schott, London: Mcmillan, 1896).

[31] Ohta, K., Amano, K., Hayashida, A., Zheng, G., and Honda, I., 2011, “Analysis of piston slap induced noise and vibration of internal combustion engine (effect of piston profile and pin offset),” J. Environment and Engineering, 6(4), pp. 765-777.

[32] Rahnejat, H., 2010, “Tribology ad dynamics of engine and powertrain: Fundamentals, applications and future trends,” Woodhead Publishing Ltd., Chapter 10.

[33] Granick, N., and Stern, J.E., 1965, “Material damping of Aluminium by a resonant-dwell technique,” NASA Technical Note, D-2893. 
[34] Crawley, E.F., and Van Schoor, M.C., 1987, “Material damping in Aluminium and metal matrix composites,” J. Comp. Mat., 21, pp. 553-568.

[35] Haddad, S.D., and Fortescue, P.W., 1977, "Simulating piston slap by an analogue computer," J. Sound and Vibration, 52(1), pp. 79-93.

[36] Cho, S.H., Ahn, S.T., and Kim, Y.H., 2002, “A simple model to estimate the impact force induced by piston slap,” J. Sound and Vibration, 255(2), pp. 229-242.

[37] Rahnejat, H., 1998, "Multi-body dynamics: vehicles, machines and mechanisms," Professional Engineering Publishing, London, ISBN 9781860581229.

[38] Vakakis, A.F., Gendelman, O.V., Bergman, L.A., McFarland, D.M., Kerschen, G., Lee, Y.S., 2008, “Nonlinear targeted energy transfer in mechanical and structural systems,” Springer Science and Business Media, 156, ISBN13:978-1-4020-9125-4.

[39] Prata, A.T., Fernandes, J.R.S., Fagotti, F., 2000, "Dynamic analysis of piston secondary motion for small reciprocating compressors,” Journal of Tribology, 122, pp. 752-760.

[40] Cho, J.R., Moon, S.J., 2005, “A numerical analysis of the interaction between the piston oil film and the component deformation in a reciprocating compressor,” Trib. Int., 38, pp. 459-468.

[41] Gohar, R., 2001, “Elastohydrodynamics,” Imperial College Press, ISBN: 1-86094-170-2.

[42] Johnson, K.L., 1985, “Contact Mechanics,” Cambridge Press, Cambridge, UK, ISBN 0521255767.

[43] Teodorescu, M., Taraza, D., Henein, N.A., Bryzik, W., 2003, "Simplified elastohydrodynamic friction model of the cam-tappet contact,” SAE Transactions, 112(3), 1271-1282.

[44] Greenwood, J.A., Williamson, J.B.P, 1966, “Contact of nominally flat surfaces,” Proc. R. Soc. Lond. A: Mathematical, Physical and Engineering Sciences, 295(1442), pp. 300-319.

[45] Greenwood, J.A., Tripp, J.H., 1970, “The contact of two nominally flat rough surfaces,” Proc. Inst. Mech. Eng., 185(1), pp. 625-633.

[46] Perera, M.S.M., 2006, "Multi-physics for integrated analysis of flexible body dynamics with tribological conjunction in IC engines,” PhD Thesis, Loughborough University, ID: ALEPH 001177990. 
[47] Dolatabadi, N., Theodossiades, S., Rothberg, S.J., 2015, “Application of nonlinear vibration absorber to the control of piston secondary motion in internal combustion engines,” Proc. ASME., IDETC/CIE, Boston, Massachusetts, USA.

[48] Haris, A., Motato, E., Mohammadpour, M., Theodossiades, S., Rahnejat, H., O’ Mahony, M., Vakakis, A.F., Bergman, L.A. and McFarland, D.M., 2017, “On the effect of multiple parallel nonlinear absorbers in palliation of torsional response of automotive drivetrain”, International Journal of Non-Linear Mechanics, 96, pp. 22 - 35

[49] Kerschen, G., Peeters, M., Golinval, J.C., Vakakis, A.F., 2009, "Nonlinear normal modes, part I: A useful framework for the structural dynamicists”, Mech. Syst. Signal Process. 23, pp. 170-194.

[50] Peeters, M., Viguié, R., Sérandour, G., Kerschen, G., Golinval, J.C., 2009, "Nonlinear normal modes, part II: Toward a practical computation using numerical continuation techniques”, Mech. Syst. Signal Process. 23, pp. 195216.

\section{List of Table Captions}

Table 1. The optimal NES design specifications for each NES mass ratio

Table 2. The average values of the objective functions for optimal NES designs

\section{List of Figure Captions}

Figure 1: Piston assembly parameters and free body diagram

Figure 2: FFT spectra of piston's secondary motions at 3000rpm: translation $\left(e_{p}\right)$ and rotation about the piston pin $(\beta)$

Figure 3: Pendulum NES coupled with the piston assembly

Figure 4: Free body diagram of the pendulum NES (external excitations and inertial forces)

Figure 5: Impact severity objective function variation with damping coefficient $c_{t}$ and stiffness coefficient $k_{t}(\varepsilon=7.5 \%)$

Figure 6: Impact severity objective function variation with damping coefficient $c_{t}$ and stiffness coefficient $k_{t}(\varepsilon=12.5 \%)$

Figure 7: Impact severity objective function variation with damping coefficient $c_{t}$ and stiffness coefficient $k_{t}(\varepsilon=20 \%)$

Figure 8: NoI objective function variation with damping coefficient $c_{t}$ and stiffness coefficient $k_{t}(\varepsilon=7.5 \%)$

Figure 9: NoI objective function variation with damping coefficient $c_{t}$ and stiffness coefficient $k_{t}(\varepsilon=12.5 \%)$

S. Theodossiades, CND-17-1339 
Figure 10: Transferred energy objective function variation with damping coefficient $c_{t}$ and stiffness coefficient $k_{t}(\varepsilon=$ $12.5 \%)$

Figure 11: Eccentricity acceleration variation with damping coefficient for (a) $7.5 \%$ and (b) $12.5 \%$ NES mass ratios (maximum $(m x)$ and minimum $(m n)$ values at the piston top $\left(e_{t}\right)$ and bottom $\left(e_{b}\right)$ lands)

Figure 12: NoI variation with damping coefficient for (a) $7.5 \%$ and (b) $12.5 \%$ NES mass ratios at the top $\left(e_{t}\right)$ and bottom $\left(e_{b}\right)$ of the piston skirt

Figure 13: Transferred energy variation with damping coefficient at (a) 7.5\% and (b) 12.5\% NES mass ratio (at TS and ATS of the cylinder liner)

Figure 14. Comparison of performance improvement for different objective functions and NES design specifications

Figure 15: Eccentricity displacements for three engine cycles (2-DOF model (black) vs. 3-DOF model (red))

Figure 16: Eccentricity accelerations for three engine cycles (2-DOF model (black) vs. 3-DOF model (red))

Figure 17: Power loss variations for the primary system (2-DOF model) and piston equipped with $12.5 \%$ mass ratio NES (3-DOF model)

Figure 18: Power loss variations for the primary system (2-DOF model) and piston equipped with 20\% mass ratio NES (3DOF model)

Figure 19: Power loss increase with respect to the primary system (without NES)

Figure 20: Frequency-energy plot of grounded pendulum and energy-wavelet cloud of the piston equipped with NES (3500 rpm and $\varepsilon=12.5 \%)$ 